
\title{
$\begin{array}{ll}\text { Research Square } & \begin{array}{l}\text { Preprints are preliminary reports that have not undergone peer review. } \\ \text { They should not be considered conclusive, used to inform clinical practice, } \\ \text { or referenced by the media as validated information. }\end{array}\end{array}$
}

\section{BRAFV600E-induced senescence drives Langerhans Cell Histiocytosis pathophysiology}

Miriam Merad ( $\nabla$ miriam.merad@mssm.edu )

Icahn School of Medicine at Mount Sinai

\section{Article}

Keywords: Langerhans cell histiocytosis, BRAFV600E, hematopoietic progenitor cells

Posted Date: November 4th, 2020

DOl: https://doi.org/10.21203/rs.3.rs-98634/v1

License: (c) (i) This work is licensed under a Creative Commons Attribution 4.0 International License. Read Full License 


\section{Abstract}

Langerhans cell histiocytosis (LCH) is a potentially fatal condition characterized by granulomatous lesions with characteristic clonal mononuclear phagocytes (MNP) harboring activating somatic mutations in MAPK pathway genes, most notably BRAFV600E. We recently discovered that the BRAFV600E mutation can also affect multipotent hematopoietic progenitor cells (HPC) in multisystem LCH disease. How BRAFV600E mutation in HPC leads to LCH is not known. Here we show that enforced expression of the BRAFV600E mutation in early mouse and human multipotent HPC induced a senescence program that led to HPC growth arrest, apoptosis resistance and senescence-associated secretory phenotype (SASP). SASP, in turn, promoted HPC skewing towards the MNP lineage leading to the accumulation of senescent MNP in tissue and the formation of $\mathrm{LCH}$ lesions. Accordingly, elimination of senescent cells using INK-ATTAC transgenic mice as well as pharmacologic blockade of SASP improved LCH disease in mice. These results identify senescent cells as a novel target for the treatment of $\mathrm{LCH}$.

\section{Introduction}

Histiocytoses are a group of conditions characterized by the accumulation of histiocytes in various tissues. Histiocytes, now more commonly known as mononuclear phagocytes (MNP), consist of heterogeneous cells of myeloid origin that include dendritic cells and macrophages. Specifically, Langerhans Cell Histiocytosis (LCH), the most common histiocytic disorder, results from the

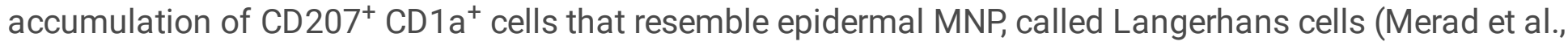
2008). LCH occurs mostly in children with an incidence of $8.9 / 10^{6}$ children per year, similar to pediatric Hodgkin's lymphoma (Stålemark et al., 2008). LCH can arise in a variety of settings from single bone lesions to life-threatening disseminated disease that affects the spleen, liver, and bone marrow (BM). Currently, front-line chemotherapy fails in more than $50 \%$ of patients with multisystem disease, highlighting the need for novel therapies for this group of patients (Allen et al., 2018). However, uncertainty with regard to disease pathophysiology as well as the paucity of a reliable LCH preclinical model have challenged the development of optimal clinical strategies for patients with aggressive LCH.

Activating somatic mutations in MAPK pathway genes, most notably BRAFV600E, have been identified in $85 \%$ cases of $\mathrm{LCH}$, specifically in the pathogenic $\mathrm{CD} 207^{+}$cells within $\mathrm{LCH}$ lesions (Badalian-Very et al., 2010; Chakraborty et al., 2014 and 2016; Lim et al., 2020). CD207 ${ }^{+}$LCH cells express many features of MNP, and in particular dendritic cells, such as expression of MHC II, CD11C, and CD207. Normal dendritic cells have a short half-life in peripheral tissues, which they leave upon expression of the chemokine receptor CCR7, following a CCL21 gradient expressed by lymphatic vessels and lymph node stromal cells that guide them to the T zone of tissue-draining lymph nodes (Merad et al., 2013). We recently showed that the BRAFV600E mutation prolonged LCH cell survival through the induction of the anti-apoptotic molecule BCL-XL and abolished CCR7 expression, thus trapping LCH cells in tissues and leading to LCH lesions (Hogstad et al., 2018). Importantly, we and others (Berres et al., 2015; Durham et al., 2017; Milne et 
al., 2017) recently discovered that the BRAFV600E mutation can also be identified in $\mathrm{CD} 34^{+} \mathrm{BM}$ hematopoietic progenitor cells (HPC) in LCH patients with systemic disease, which has led to the reclassification of multi-focal LCH as a myeloid neoplasia (Allen et al., 2018; Berres et al., 2015; Lim et al., 2020). These new results revealed a new conundrum in LCH pathophysiology: how does the somatic $B R A F \mathrm{~V} 600 \mathrm{E}$ mutation in multipotent progenitor cells lead to $\mathrm{LCH}$ lesions?

HPC differentiate into lymphoid and myeloid lineages in response to cell intrinsic and extrinsic cues in the BM. Once committed to the myeloid lineage, HPC can either differentiate into the granulocytic or the MNP lineage, the latter of which gives rise to dendritic cells, monocytes, monocyte-derived dendritic cells, and monocyte-derived macrophages (Merad et al., 2013).

Here, we explored the mechanisms by which, the BRAFV600E mutation could potentially drive a multipotent hematopoietic progenitor to give rise to LCH lesions. Strikingly, we found that enforced expression of the BRAFV600E mutation in early mouse and human multipotent HPC induced a senescence program that led to HPC growth arrest, apoptosis resistance, and senescence-associated secretory phenotype (SASP) induction. This SASP, in turn, promoted multipotent HPC skewing towards the MNP lineage away from other hematopoietic lineages. BRAFV600E-induced senescence persisted in differentiated MNP that accumulated in tissues, where SASP induction and sustained MNP survival contributed to the formation of LCH lesions. Accordingly, we found that genetic elimination of senescent cells using INK-ATTAC transgenic mice, as well as pharmacologic blockade of SASP, improved LCH disease burden in mice. These results transform our understanding of LCH pathophysiology, and identify senescent cells as a novel target for the treatment of $\mathrm{LCH}$.

\section{Results}

\section{Expression of the BRAFV600E mutation in mouse multipotent hematopoietic progenitor cells (HPC) is sufficient to drive to $\mathrm{LCH}$ lesion formation}

We previously identified that the BRAFV600E mutation is found not only in $\mathrm{LCH}$ lesions, but also in $\mathrm{CD} 34^{+}$ $\mathrm{BM} \mathrm{HPC}$ and blood circulating $\mathrm{CD} 11 \mathrm{c}^{+}$and $\mathrm{CD} 14^{+}$monocytes in patients with multi-system $\mathrm{LCH}$ (Berres et al., 2015). These results prompted us to explore how expression of the BRAFV600E mutation in multipotent HPC could lead to LCH lesions. To examine whether BRAFV600E ${ }^{+} \mathrm{HPC}$ can drive LCH lesions, we enforced expression of the BRAFV600E mutation in cells expressing $\mathrm{Scl}$ (also known as Tal1), a molecule expressed specifically in long-term and short- term hematopoietic stem cells (HSC) in mice (Göthert et al., 2005). We genetically engineered somatic mosaicism for a BRAFV600E allele linked to a yellow fluorescent protein (YFP) in HSC using tamoxifen (Tam)-inducible targeting in Sclcre-ER mice, which we named $B R A F \mathrm{~V} 600 \mathrm{E}^{\mathrm{Scl}+}$, and used $B R A F \mathrm{wt}^{\mathrm{Scl}+}$ as control littermates (Figure $1 \mathrm{~A}$ ). Thus, Rosa ${ }^{\mathrm{YFP}+}$ cells carried the BRAFV600E mutation in BRAFV600 $\mathrm{E}^{\mathrm{Scl}+}$ mice, whereas Rosa ${ }^{\mathrm{YFP}+}$ cells in BRAFwt ${ }^{\mathrm{Scl}+}$ mice did not carry the mutation but underwent Rosa26-locus driven cre recombination. Tamoxifen (Tam) pulsedadministration led to YFP expression in $30 \%$ of $\mathrm{HSC}$ providing the opportunity to compare BRAFV600E 
$\left(\mathrm{YFP}^{+}\right)^{\mathrm{Scl}+}$ cells to BRAFwt(YFP) $)^{\mathrm{Scl}+}$ cells within the same mouse (Fig 1B). Strikingly, BRAFV600E ${ }^{\mathrm{Scl}+}$ mice developed substantial organomegaly, granulomatous bone lesions and BM aplasia within 4 weeks of Tam administration, while BRAFwt ${ }^{S c l+}$ control littermates did not (Fig $1 \mathrm{C}$, Supplementary Fig $1 \mathrm{~A}, \mathrm{~B}$ and C). Histological analysis of hematoxylin \& eosin (H\&E) stained formalin-fixed paraffin-embedded (FFPE) tissue sections revealed an accumulation of histiocytes within granulomatous lesions, multinucleated giant cells and an inflammatory infiltrate in the liver, lungs and dermis of $B R A F \mathrm{~V} 600 \mathrm{E}^{\mathrm{SCl}+}$ mice (Fig 1D, Sup Fig 1D). Immunohistochemistry analysis revealed that many histiocytes express CD207 (Fig 1D). Lesions were diagnosed as LCH by a clinical pathology expert blinded to the experiment. Flow cytometry analysis confirmed the significantly increased immune cell infiltrate and the expansion of the MNP compartment within the immune cell infiltrate (Fig 1F, Sup Fig 1E). Importantly, in the skin, MNP mostly accumulated in the dermis and were absent from the epidermis (Fig 1F), mimicking the dermotropism of the human disease. Flow cytometry analysis also revealed the preferential expansion of MNP within the BRAFV600E ${ }^{\mathrm{YFP}+}$ immune cell compartment in tissues known as targets of $\mathrm{LCH}$ lesions (Fig 1E and Sup Fig 1F).

\section{Humanized mice reconstituted with human $\mathrm{CD} 34^{+} \mathrm{HPC}$ expressing the BRAFV600E mutation develop LCH-like disease}

To determine whether expression of the BRAFV600E mutation in human HPC could also lead to LCH disease, we generated a lentiviral vector expressing the green fluorescent reporter (GFP) together with the BRAFV600E mutation (BRAFV600E ${ }^{\text {hu }}$ ) or the NGFR truncated gene (NGFR ${ }^{\text {hu }}$ ) under the EF-1 alpha 1 (EF1A1) promoter (Sup Fig 1G). HPC transduction efficiency, around 40\%, led to sustained ERK phosphorylation in BRAFV600E ${ }^{\text {hu }}$ but not in NGFR ${ }^{\text {hu }} \mathrm{HPC}$ (Sup Fig $1 \mathrm{H}$ and I). We reconstituted sublethally irradiated 8-week old NOD-SCID gamma (NSG) mice with human CD $34^{+}$cord blood HPC transduced with this lentiviral vector (Fig 1G). NSG mice deteriorated within two months following reconstitution with BRAFV600 ${ }^{\text {hu }} \mathrm{CD} 34^{+} \mathrm{HPC}$, but not NGFR ${ }^{\text {hu }} \mathrm{CD} 34^{+} \mathrm{HPC}$, and developed an expansion of blood circulating CD11 $\mathrm{c}^{+} \mathrm{CD} 14^{+}$MNP cells (Sup Fig $1 \mathrm{~J}$ ) accompanied with an accumulation of CD $1 \mathrm{a}^{+}$ CD207 ${ }^{+}$cells in the liver, lung and spleen pathognomonic of $\mathrm{LCH}$ disease $(\mathrm{Fig} 1 \mathrm{H})$. These results, together with our data showing that BRAFV600 $\mathrm{E}^{\mathrm{Scl}+}$ mice develop $\mathrm{LCH}$-like lesions, establish that expression of the $B R A F \mathrm{~V} 600 \mathrm{E}$ mutation in mouse and human early HPC is sufficient to drive $\mathrm{LCH}$ lesion formation.

\section{$B R A F \mathrm{~V} 600 \mathrm{E}$ HPC differentiate predominantly toward the mononuclear phagocyte (MNP) lineage}

To explore how the BRAFV600E mutation in early HPC, which should retain their multipotent lineage capabilities, drives the specific accumulation of MNP in the periphery, we measured the differentiation potential of BRAFV600E+ YFP+ HPC in BRAFV600 $\mathrm{E}^{\mathrm{Scl}+}$ mice. Strikingly, we found that BRAFV600E $\mathrm{E}^{+} \mathrm{HSC}^{-}$ and multipotent progenitors (MPP) were reduced, while $B R A F \mathrm{~V} 600 \mathrm{E}^{+}$granulocyte-macrophage progenitor 
(GMP) were significantly expanded in the BM compared to BRAFwt progenitors (Fig 2A) suggesting that the $B R A F \mathrm{~V} 600 \mathrm{E}^{+} \mathrm{HPC}$ failed to expand and were instead biased towards the myeloid lineage. The expansion of $B R A F \mathrm{~V} 600 \mathrm{E}^{+} \mathrm{GMP}$ was associated with a remarkable expansion of $\mathrm{BM} B R A F \mathrm{~V} 600 \mathrm{E}^{+}$ monocytes, macrophages and dendritic cells, whereas BM BRAFV600 $\mathrm{E}^{+}$neutrophils did not expand (Fig $2 \mathrm{~B})$. To directly examine whether the BRAFV600E mutation skewed HPC commitment to the MNP lineage, we cultured purified HPC from $B R A F \mathrm{~V} 600 \mathrm{E}^{\mathrm{Scl}+}$ or $B R A F \mathrm{wt}{ }^{\mathrm{SCl}+}$ mice in methylcellulose and measured HPC progeny using a colony forming unit (CFU) assay that reflects the differentiation into committed progenitors. Consistent with the lineage bias observed in vivo, we found that BRAFV600E HPC preferentially differentiated into CFU consisting of macrophage progenitors (CFU-M), while the numbers of granulocytic progenitors (CFU-G) and erythroid progenitors also called burst forming unit-erythroid (BFU-E) were reduced (Fig 2C).

We also examined whether the BRAFV600E mutation affected human HPC lineage commitment. Consistent with the results obtained from murine BRAFV600E ${ }^{\mathrm{Scl}+} \mathrm{HPC}$, we found that human $B R A F \mathrm{~V} 600 \mathrm{E}^{\text {hu }} \mathrm{HPC}$ preferentially differentiated into the MNP lineage (Fig 2D). Remarkably, using the same CFU assay applied in mice, we found that human BRAFV600 $\mathrm{E}^{+} \mathrm{HPC}$ differentiated preferentially into CFU-GM and CFU-M colonies but not into CFU-G colonies, whereas NGFR ${ }^{+}$HPC retained a pluripotent differentiation potential (Fig 2E and Sup Fig 2). Gene expression profiling of human BRAFV600E $\mathrm{GFFP}^{+}$ and control NGFR ${ }^{+} \mathrm{GFP}^{+} \mathrm{HPC}$ seven days after culture in stem-cell media revealed enrichment for an MNP signature in BRAFV600 ${ }^{+} \mathrm{HPC}$ that included the expression of the classical dendritic cells genes (BATF3, IRF4, CLEC1OA) as well as the macrophage genes (CSF1R, CD68, SPP1), while HPC differentiation into granulocytes was strongly reduced compared to control NGFR ${ }^{+} \mathrm{HPC}$ (Fig 2F).

To further confirm the MNP skewing of $B R A F V 600 \mathrm{E}^{+} \mathrm{HPC}$ in LCH patients, we performed RNA sequencing of purified $\mathrm{CD}_{3} 4^{+} \mathrm{HPC}$ isolated from the BM of LCH patients (Supplementary Table 1). Similar to the signature of BRAFV600E transduced HPC, $\mathrm{CD} 34^{+} \mathrm{HPC}$ isolated from $\mathrm{LCH}$ patients showed reduced expression of genes associated with granulopoiesis (ELANE, MPO, PRTN3, CSF3R), and an increased expression of genes involved in dendritic cells/macrophages commitment (BATF3, IRF4, CSF1R, CLEC10A) compared to CD34 $\mathrm{HPC}$ isolated from an age- matched individual (Fig 2G). Taken together, these data establish that the BRAFV600E mutation directs mouse and human HPC to differentiate into the MNP lineage away from the lymphoid and the granulocytic lineage.

\section{The skewing of $B R A F \mathrm{~V} 600 \mathrm{E}^{+} \mathrm{HPC}$ into the MNP lineage is driven by both cell intrinsic and extrinsic cues}


To examine whether the enhanced MNP differentiation of $B R A F \mathrm{~V} 600 \mathrm{E}^{+} \mathrm{HPC}$ was cell intrinsic or a result of external cues, we measured the expansion of BRAFV $600 \mathrm{E}^{+}$and $B R A F \mathrm{Wt} \mathrm{HPC}$ within the same animal. Strikingly, while we failed to observe an expansion of GMP in $B R A F w t^{S c l+}$ mice, there was an expansion of $B R A F \mathrm{~V} 600 \mathrm{E}^{+}$and $B R A F \mathrm{wt} \mathrm{GMP}$ within the same BRAFV600E $\mathrm{E}^{\mathrm{Scl}+}$ mice $(\mathrm{Fig} 2 \mathrm{H})$, associated with an increase of BM BRAFV600 $\mathrm{E}^{+}$and BRAFwt MNP but not neutrophils (Fig 2I). The expansion of BM BRAFwt $\mathrm{MNP}$ in $B R A F \mathrm{~V} 600 \mathrm{E}^{\mathrm{Scl}+}$ mice but not in $B R A F \mathrm{wt}^{\mathrm{Scl}+}$ mice suggest that MNP skewing may not only be driven by cell intrinsic cues.

To examine whether similar cell extrinsic cues can also drive human HPC differentiation into MNP, we took advantage of the fact that HPC transduction efficiency with BRAFV600E or NGFR lentiviral vectors did not exceed $40 \%$ (Sup Fig 1G), to compare within the same culture the differentiation of BRAFV600E ${ }^{+} \mathrm{GFP}^{+}$and BRAFV600E-GFP' ${ }^{-}$as well as NGFR ${ }^{+} \mathrm{GFP}^{+}$and NGFR'GFP- $\mathrm{HPC}$. Similar to our mouse results, BRAFV600 $\mathrm{E}^{-} \mathrm{GFP}^{-}$cells co-cultured with $B R A F \mathrm{~V} 600 \mathrm{E}^{+} \mathrm{GFP}^{+}$cells had an enhanced $\mathrm{MNP}$ differentiation potential, although at a reduced scale compared to $B R A F \mathrm{~V} 600 \mathrm{E}^{+} \mathrm{GFP}^{+} \mathrm{HPC}$ counterparts (Fig 2J). This contrasts with our earlier results showing that purified human BRAFV600E-GFP- HPC cultured alone in CFU assays did not have an MNP differentiation advantage (Fig 2E, Sup Fig 2). This suggests that secreted molecules produced by $B R A F \mathrm{~V} 600 \mathrm{E}^{+} \mathrm{GFP}^{+} \mathrm{HPC}$ contributed to driving MNP differentiation of healthy HPC. To directly measure whether the BRAFV600E ${ }^{+} \mathrm{HPC}$ secretome skewed the differentiation of BRAFwt HPC toward the MNP lineage, we cultured human CD34 ${ }^{+} \mathrm{HPC}$ in stem-cell media in the presence or absence of supernatant isolated from human BRAFV600E $\mathrm{E}^{+} \mathrm{HPC}$ or $\mathrm{NGFR}^{+} \mathrm{HPC}$ Consistent with our hypothesis, we observed that healthy HPC cultured in the presence of supernatant

obtained from human BRAFV600E $\mathrm{E}^{+} \mathrm{HPC}$ cultures were more prone to differentiate into MNP compared to healthy HPC cultured in the presence of NGFR ${ }^{+} \mathrm{HPC}$ supernatant, and that the enhanced MNP differentiation potential was dependent on the dose of $B R A F \mathrm{~V} 600 \mathrm{E}^{+} \mathrm{HPC}$ supernatant added (Fig $2 \mathrm{~K}$ ).

\section{The BRAFV600E mutation drives mouse and human hematopoietic progenitors into oncogene-induced senescence}

The realization that the BRAFV600E mutation limited the expansion of HSC (Fig 2A) prompted us to further assess the proliferation potential of $B R A F \mathrm{~V} 600 \mathrm{E}$ mutant HPC using a competitive reconstitution assay in which, purified $B R A F \mathrm{~V} 600 \mathrm{E}^{+} \mathrm{HPC}$ or BRAFwt HPC (isolated from $\mathrm{CD} 45.2^{+}$animals) were injected together with host $\mathrm{HPC}\left(\mathrm{CD} 45.1^{+}\right)$at a 2:1 ratio into sub-lethally irradiated CD $45.1^{+}$recipients. Strikingly, we found that at 4 and 8 weeks after transplantation, the number of engrafted $B R A F V 600 \mathrm{E}^{+} \mathrm{HPC}$ was strongly reduced compared to BRAFwt HPC (Fig 3A, Sup Fig 3A), thus revealing the proliferative disadvantage of BRAFV600E HPC compared to BRAFwt HPC. 
The BRAFV600E mutation has been previously described to drive cellular senescence in human naevi lesions (Michaloglou et al., 2005). Cellular senescence classically occurs secondary to DNA damage or because of oncogene-activation and results in cell cycle arrest driven by cell cycle regulators such as p16 ${ }^{\text {INK4a }}$, prolonged survival driven by the anti-apoptotic proteins $\mathrm{Bcl}-\mathrm{xL}$ and $\mathrm{Bcl}-2$. Senescent cells also form heterochromatin foci, and express senescence-associated b galactosidase (SAbGal), as well as a senescence-associated secretory phenotype (SASP) (reviewed in (Hernandez-Segura et al., 2018; MuñozEspín and Serrano, 2014)), which leads to the production of a wide range of inflammatory molecules such as IL-1, IL-6, IL-8 and several matrix metalloproteinases. Furthermore, senescence results in morphological alterations with senescent cells being enlarged with an irregular shape.

Strikingly, we found that $B R A F \mathrm{~V} 600 \mathrm{E}^{\mathrm{Scl}+} \mathrm{HPC}$ were unable to cycle, as shown by the low BrdU incorporation potential which, likely accounts for their poor ability to engraft compared to BRAFwt ${ }^{S c l+}$ mice in a competitive reconstitution assay (Fig 3B). HPC isolated from $B R A F \mathrm{~V} 600 \mathrm{E}^{\mathrm{Scl}+}$ mice were also enlarged compared to HPC from BRAFwt ${ }^{\mathrm{Scl}+}$ mice, a common feature of senescent cells (Sup Fig 3B); expressed high levels of $C D K N 2 A$ transcripts which codes for cell cycle regulator p16 ${ }^{1 \mathrm{NK} 4 \mathrm{a}}$ (Fig $3 C$ ), were positive for SAbGal (Fig 3D); and produced SASP-associated proteins (Fig 3E), all features consistent with a senescent state. $\mathrm{LCH}$ cells isolated from peripheral tissues of $B R A F \mathrm{~V} 600 \mathrm{E}^{\mathrm{Scl}+}$ mice were also in a senescent state, as shown by reduced Ki-67 expression (Fig 3F), expression of CDKN2A (Fig 3G), SAbGal activity (Fig $3 \mathrm{H}$ ) and the production of SASP-associated proteins (Fig $3 \mathrm{I})$. These results suggest that the $B R A F \mathrm{~V} 600 \mathrm{E}$ mutation induced a senescence program in HPC which was maintained in differentiated $\mathrm{LCH}$ cells.

Similar to mice, the BRAFV600E mutation in human HPC led to an initial phase of proliferation (Sup Fig 3C) followed by a marked cell-cycle arrest in vitro (Fig 3J, Sup Fig 3D). Human BRAFV600E transduced HPC expressed canonical markers of cellular senescence including enlarged cellular size (Sup Fig 3E), positivity for SAbGal staining (Fig 3L), senescence-associated heterochromatin foci (Fig 3M) and increased production of SASP cytokines (Fig 3N, Sup Fig 3F). Gene expression profiling of transduced human BRAFV600E $\mathrm{GFP}^{+} \mathrm{HPC}$ confirmed the senescence signature (Kuilman et al., 2008) (Fig 3K) and $\mathrm{LCH}$ lesions that formed in humanized mice reconstituted with human BRAFV600E CD34 ${ }^{+}$cells also expressed SAbGal activity and high p16 ${ }^{\text {INK4a }}$ levels (Sup Fig $3 G$ and $H$ ).

Importantly, $\mathrm{CD} 34^{+} \mathrm{BM}$ cells isolated from $\mathrm{LCH}$ patients also expressed a senescence signature including increased expression of $C D K N 2 A, C D K N 2 C, C D K N 2 D, C D 9, M D M 2$, and matrix- metalloproteinases, which 
was absent from CD34+ BM cells isolated from age-matched healthy individuals (Fig 4A and Sup Fig 4A).

Purified $\mathrm{CD} 207^{+}$cells from human $\mathrm{LCH}$ lesions expressed high $C D K N 2 A, C D K N 2 B, C D K N 2 C$ transcripts and high SASP transcript levels (MMP1, MMP3, MMP9, MMP13) (Fig 4B). LCH cells from LCH lesions expressed low level or no Ki-67 (Fig 4C) while they expressed high levels of p16 ${ }^{\text {INK4a }}$ protein expression and high SAbGal activity (Fig 4D, E and Sup Fig 4B, C). In addition, we found high IL-6 and IL-8 cytokine levels in the plasma of LCH patients with multisystem disease (Fig 4F).

A neurodegenerative syndrome (LCH-ND) characterized by progressive ataxia, learning and behavior difficulties arises in some patients with $\mathrm{LCH}$ and remains one of the most difficult to treat $\mathrm{LCH}$ complication. We previously demonstrated the presence of $B R A F \mathrm{~V} 600 \mathrm{E}^{+}$perivascular microglial-like cells along with blood circulating BRAF $600 \mathrm{E}^{+}$mononuclear cells in patients with $\mathrm{LCH}-\mathrm{ND}$. To determine whether senescence could also contribute to LCH-ND pathophysiology, we examined brain autopsy sections of a patient with fatally progressive ND-LCH (McClain et al., 2018). Strikingly, we found multifocal aggregates of enlarged $B R A F \mathrm{~V} 600 \mathrm{E}^{+}$cells expressing monocyte-macrophage markers (CD14 ${ }^{+}$, $\mathrm{CD}_{163^{+}}, \mathrm{CD}_{3} 3^{+}$) overexpressing the senescent marker $\mathrm{p} 16^{\mathrm{INK} 4 \mathrm{a}}$ aggregating in areas of the white matter (Fig 4G). These cells also lacked the microglial marker (P2RY12, Sup Fig 4E) and accumulated in perivascular regions suggesting that senescent circulating MNP that are recruited from the blood to the brain parenchyma rather than brain resident microglial cells contribute to ND in this patient.

Taken together, these data suggest that the BRAFV600E mutation induces a senescence program in HPC that persisted in differentiated LCH cells that accumulate in the peripheral tissue sand brain parenchyma.

\section{Pharmacological blockade of mTOR pathway inhibits SASP induction and limits MNP differentiation of BRAFV600E ${ }^{+} \mathrm{HPC}$}

Our results above suggesting that the secretome produced by $B R A F \mathrm{~V} 600 \mathrm{E}^{+} \mathrm{HPC}$ contributed to the skewing of HPC toward the MNP lineage, prompted us to examine whether SASP inhibition could help rescue HPC multi-lineage differentiation potential. SASP includes a wide range of cytokines that can contribute to MNP skewing and therefore targeting a specific cytokine might not be sufficient to obtain a therapeutic benefit. SASP induction in senescent cells is thought to be driven by the sustained activation of the mammalian target of rapamycin (mTOR) pathway (Herranz et al., 2015; Laberge et al., 2015). Thus, we asked whether rapamycin, a potent mTOR inhibitor could, could reduce MNP differentiation skewing of $B R A F \mathrm{~V} 600 \mathrm{E}^{+}$senescent HPC by its ability to blunt the pro-inflammatory phenotype of senescent cells. 
We first confirmed that inhibition of the mTOR pathway was sufficient to reduce the production of inflammatory cytokines by BRAFV600E ${ }^{+} \mathrm{HPC}$ senescent cells in vitro (Fig 5A). Importantly, and in line with our hypothesis, SASP inhibition significantly reduced $B R A F \mathrm{~V} 600 \mathrm{E}^{+} \mathrm{HPC}$ skewing into MNP in vitro (Fig 5B). Rapamycin treatment also partially reduced excess MNP differentiation from BRAFV600E-GFP$\mathrm{HPC}$ co-cultured with senescent $B R A F \mathrm{~V} 600 \mathrm{E}^{+} \mathrm{GFP}^{+} \mathrm{HPC}$, further establishing that mTOR inhibition reduced the release of SASP-associated molecules driving HPC sustained MNP differentiation potential (Fig 5B).

Importantly, rapamycin administration to $B R A F \mathrm{~V} 600 \mathrm{E}^{\mathrm{Scl}+}$ mice reduced the accumulation of $\mathrm{BM} \mathrm{GMP}$ and MNP, while BM neutrophils were not affected by the treatment (Fig 5C, D and Sup Fig 5A). Rapamycin administration reduced organomegaly in $B R A F \mathrm{~V} 600 \mathrm{E}^{\mathrm{Scl}+}$ animals (Fig $5 \mathrm{E}$ ) and the inflammatory infiltrate in tissues (Fig 5F), improving LCH disease. Of note, rapamycin did not induce apoptosis of BRAFV600E ${ }^{+}$ cells (Sup Fig 5B). While we cannot exclude that improved LCH disease in treated BRAFV600E $\mathrm{E}^{\mathrm{SCl}+}$ animals may also be linked to a direct effect of rapamycin on T cells-infiltrating LCH lesions, the ability of rapamycin to inhibit the release of inflammatory cytokines from BRAFV600E HPC and the MNP skewing induced by secreted factors of $B R A F \mathrm{~V} 600 \mathrm{E}^{+} \mathrm{HPC}$, in addition to rapamycin inhibition of GMP and MNP accumulation in the $\mathrm{BM}$ of $B R A F \mathrm{~V} 600 \mathrm{E}^{\mathrm{Scl}+}$ animals, emphasizes the strong contribution of mTOR-driven SASP to the increased MNP differentiation observed in mice and human BRAFV600E HPC.

\section{Elimination of senescent cells improves the clinical outcome of LCH bearing mice}

To measure the exact contribution of senescence to $\mathrm{LCH}$ pathogenesis, we took advantage of mice expressing the INK-ATTAC transgene (inducible elimination of $\mathrm{p} 16^{\mathrm{INK} 4 \mathrm{a}}$-positive senescent cells upon administration of AP20187) generated as described (Baker et al., 2011). The INK-ATTAC transgene includes an open reading frame (ORF) coding for the enhanced green fluorescence protein (eGFP) and the FK506-binding-protein-caspase 8 (FKBP-Casp8) fusion protein, expressed under the promoter of the CDKN2A gene, which encodes for $\mathrm{p} 16^{\mathrm{INK} 4 \mathrm{a}}$ protein. These mice enable $C D K N 2 A / \mathrm{p} 16^{\text {INK4a+ }}$ senescent cells to be visualized based on GFP expression and conditionally deleted upon administration of AP20187 (AP), a synthetic drug that induces the dimerization of a membrane-bound myristoylated FKBP-Casp8 leading to the apoptosis of Caspase 8 expressing cells.

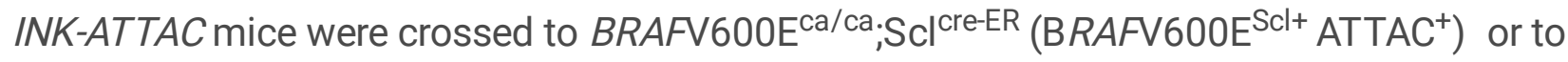

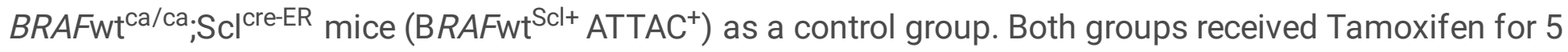


days to induce LCH lesions and we measured the accumulation and composition of senescent cells in the BM (Fig 5G). In line with our previous results, we observed a significant accumulation of $\mathrm{GFP}^{+}$senescent cells in the bone marrow of $B R A F \mathrm{~V} 600 \mathrm{E}^{\mathrm{SCl}+} \mathrm{ATTAC}^{+}$animals compared to $B R A F \mathrm{wt}{ }^{\mathrm{Scl+}} \mathrm{ATTAC}^{+}$control littermates $(\mathrm{Fig} 5 \mathrm{H})$. The majority of bone marrow $\mathrm{GFP}^{+}$senescent cells were skewed towards the MNP lineage and led to enhanced accumulation of senescent macrophages and dendritic cells but not neutrophils in BRAFV600 ${ }^{\mathrm{SCl}+} \mathrm{ATTAC}^{+}$compared to BRAFwt ${ }^{\mathrm{SCl}+} \mathrm{ATTAC}^{+}$mice (Fig 5I). BRAFV600 $\mathrm{E}^{\mathrm{Scl}+}$ $A T T A C^{+}$were then treated with AP to delete senescent cells or with the vehicle control for 3 weeks. AP treatment cleared $\mathrm{GFP}^{+}$cells from the bone marrow of $B R A F \mathrm{~V} 600 \mathrm{E}^{\mathrm{Scl}+} \mathrm{ATTAC}^{+}$mice (Fig 5J). Importantly, clearance of $\mathrm{GFP}^{+}$senescent cells from $B R A F V 600 \mathrm{E}^{\mathrm{Scl}+} \mathrm{ATTAC}^{+}$reduced organomegaly of $\mathrm{LCH}$-bearing mice (Fig $5 \mathrm{~K}$ ) and reduced the immune infiltrate in liver and lung tissues (Fig $5 \mathrm{~L}$ ), showing that senescent cells are responsible of LCH pathophysiology.

Finally, to further examine whether pharmacological elimination of senescent cells can improve LCH outcome, we used ABT-263 a specific inhibitor of the anti-apoptotic proteins BCL-2 and BCL-xL, which are both highly expressed in senescent cells. While not specific to senescent cells, ABT-263, was shown to improve the clinical outcome of several senescence -associated diseases (Bussian et al., 2018; Chang et al., 2016; Jeon et al., 2017). Similar to most senescent cells, BCL-2 and BCL-xL are highly expressed in $B R A F \mathrm{~V} 600 \mathrm{E}^{+} \mathrm{HPC}$ and $\mathrm{LCH}$ cells in peripheral tissues. We had previously shown that inhibition of $\mathrm{BCL}-\mathrm{xL}$ can efficiently eliminate LCH cells (Hogstad et al., 2018). Here we asked whether ABT-263 administration can improve outcome in $\mathrm{LCH}$ bearing mice. We administered ABT-263 to BRAFV600 $\mathrm{E}^{\mathrm{SCl}+}$ animals or $B R A F \mathrm{wt}^{\mathrm{SCl}+}$ control littermates for 3 weeks (Sup Fig $5 \mathrm{C}$ ). ABT-263 diluent prevents its systemic administration and both gavage of ABT-263 or diluent control are quite toxic to mice making it difficult to measure the beneficial outcome of ABT-263 in treated mice. Nonetheless and in accordance with ex vivo experiment, we found in $B R A F \mathrm{~V} 600 \mathrm{E}^{\mathrm{Scl}+}$ mice that were able to survive, specific clearance of $B R A F \mathrm{~V} 600 \mathrm{E}^{+}$ cells (Sup Fig 5D), reduced organomegaly (Sup Fig 5E) and reduced immune lung infiltrate (Sup Fig 5F) in mice treated with ABT-263. These results suggest that ABT-263 could provide a novel clinical strategy to treat $\mathrm{LCH}$ patients either alone or in combination with BRAF inhibitors.

\section{Discussion}

Using genetically engineered mouse models and humanized mouse models, we demonstrate that expression of the BRAFV600E mutation in mouse and human HPC is sufficient to drive the formation of $\mathrm{LCH}$ lesions with a tissue distribution comparable to human systemic $\mathrm{LCH}$. We also showed that enforced $B R A F \mathrm{~V} 600 \mathrm{E}$ mutation in mice and human HPC as well as primary human $\mathrm{CD} 34^{+}$hematopoietic progenitors isolated from $\mathrm{LCH}$ patients are in a senescent state and that BRAFV600E-induced senescence in hematopoietic progenitors contribute to LCH pathophysiology. Finally, using the INK-ATTAC transgene, we confirmed the accumulation of senescent cells in the bone marrow and demonstrate that depletion of senescent cells in LCH bearing mice improves disease outcome. 
Our findings showing that BRAFV600E-induced HPC senescence contributes to $\mathrm{LCH}$ lesions shed light into key features of LCH disease, such as (1) the accumulation of poorly proliferative MNP driven by the expression of the senescent- associated cell cycle inhibitor p $16^{I N K 4 a}$, and (2) the large immune infiltrate, with subsequent fibrotic injuries that accumulates in LCH lesions, which we show is driven by SASP ${ }^{+}$ senescent LCH cells.

We have previously generated a mouse model in which, one allele of BRAFV600E was induced under the CD11c promoter expressed by MNP progenitors and mature dendritic cells (Berres et al., 2015). In that model, mice developed LCH-like disease in the spleen, lung and liver but only minimal disease in the skin and bones, which was surprising as human LCH lesions frequently involve skin and bone tissues (Berres et al., 2015). In the current study, we showed that when BRAFV600E mutation was driven by the Scl promoter, expressed in pluripotent hematopoietic progenitors upstream of the MNP progenitors (BRAFV600 $\mathrm{E}^{\mathrm{Scl}+}$ mice), mice developed - in addition to $\mathrm{LCH}$-like lesions in the spleen, lung and liver tissues - skin lesions in the dermis that mimicked human LCH lesions, as well as granulomatous lesions, indicating that expression of the BRAFV600E mutation at the HSC level drives a more clinically relevant $\mathrm{LCH}$ - phenotype than the disease that forms upon induction of the BRAFV600E mutation in MNP progenitor stage.

The BRAFV600E oncogene-induced senescence is best known for its ability to protect human naevi from malignant transformation through the induction of cell cycle arrest (Michaloglou et al., 2005). In this study, we showed that expression of the BRAFV600E oncogene in early hematopoietic progenitors also promotes the induction of a senescence program and that senescence contributes to shaping the $\mathrm{LCH}$ phenotype. Cellular senescence refers to a cellular state of irreversible cell cycle arrest induced by various cell stressors such as oncogenes. The molecular effectors of senescence include the activation of canonical tumor suppressors like p $16^{\mathrm{INK} 4 \mathrm{a}}$ and $\mathrm{p} 53$. This event leads to an arrest in proliferation that prevents senescent cells from re-entering the cell cycle, while also undergoing anabolic processes driven by high levels of stress-induced nutrient-dependent mTOR activation. The senescent cell signature includes positivity for SAbGal staining, expression of the cell cycle inhibitor CDKN2A (p16 ${ }^{\mathrm{INK} 4 \mathrm{a}}$ ), and the production of mTOR-driven inflammatory cytokines including IL-1, IL-6, IL-8, as part of a SASP program. We show here that BRAFV600E HPC have a much lower proliferative capacity in vitro and in vivo which likely explains their decreased ability to engraft in competitive transplant assays when compared to wild type HPC (Fig 3A). Instead, they are more prone to differentiate into pathogenic BRAFV600E senescent MNP, which persist in tissues for prolonged periods of time where they continue to release SASP-driven cytokines. The senescence program explains poorly understood features of $\mathrm{LCH}$ cells including their reduced proliferation rate and the production of inflammatory cytokines that have been widely reported in 
patients (Allen et al., 2010, 2018). The SASP-driven cytokine production also contributes to subsequent fibrotic injury, which at critical sites (i.e. CNS including pituitary, hepatic bile ducts) leads to LCH morbidities. In addition to inducing senescence, our previous findings that BRAFV600E expression downregulates CCR7 expression in LCH cells and traps them in peripheral tissues may further contribute to their pathogenic accumulation locally (Hogstad et al., 2018).

While $C D K N 2 A / B$ deletion has never been described in $\mathrm{LCH}$ lesions, clonal deletion of $C D K N 2 A / B$ have been described in Langerhans Cell Sarcoma (Xerri et al., 2018), a rare and highly aggressive disease defined by potent histiocyte proliferation with cytologic atypia and increased mitotic index. These results suggest that $B R A F \mathrm{~V} 600 \mathrm{E}-$ induced senescence likely protects $\mathrm{LCH}$ cells from malignant transformation, similar to what has been observed in melanocytic naevi.

The nature of the inflammatory infiltrate in LCH lesions, while well-known and widely described (Picarsic and Jaffe, 2015), has remained poorly understood, prompting several groups to search for a microbial origin of LCH (McClain et al., 1994; Jenson et al., 2000). Here we showed that it is instead the SASP program that drives the release of inflammatory cytokines in BM HPC and differentiated cells in the periphery. We also showed that the senescence-driven cytokine release by BM HPC drives the induction of a MNP-differentiation program. SASP is thought to be induced upon mTOR activation, which is activated in senescent cells upon stress-induced cell cycle arrest. The release of inflammatory cytokines not only promotes the differentiation of HPC into MNP cells, but also likely contributes to the development of granulomatous lesions in peripheral tissues, common in LCH lesions, and subsequent fibrotic injury. mTOR inhibition by rapamycin has been shown to reduce SASP expression (Herranz et al., 2015; Laberge et al., 2015). In accordance with these studies, we found that mTOR inhibition reduced HPC skewing toward the MNP lineage and improved disease phenotype in vivo. Altogether, our results showing that SASP contributes to enhanced myeloid cell differentiation in the BM, could explain the myeloid-biased hematopoiesis observed in aged patients (reviewed in (Montecino-Rodriguez et al., 2013)) and if confirmed could suggest that mTOR inhibition in HPC could help restore immune balance and homeostasis in older patients.

Systemic LCH can lead to severe morbidity in patients including an increased risk of neurodegenerative syndrome (LCH-ND) that can arise years after patients are presumably cured (Allen et al., 2018). The pathogenesis of the ND syndrome in LCH patients remains poorly understood and a clinical unmet need in LCH patients. Recent studies in mice suggest that BRAFV600E expression in murine embryonic erythromyeloid-progenitor (EMP) can lead to a neurodegenerative inflammatory disorder without systemic involvement (Mass et al., 2017), although this is rarely the case in patients where LCH-ND arises more 
frequently in patients with longer periods of uncontrolled disease (reviewed in (Haroche et al., 2017; Yeh et al., 2018)).

We recently found that circulating $B R A F \mathrm{~V} 600 \mathrm{E}^{+}$monocytes are present in higher frequency at all stages of LCH-ND suggesting that LCH-ND patients likely harbor BRAFV600E ${ }^{+} \mathrm{HPC}$ in the BM (McClain et al., 2018). In addition, we also identified diffuse perivascular infiltration of $B R A F V 600 \mathrm{E}^{+}$cells with monocyte phenotype lacking microglial markers in the brain tissue of patient with LCH-ND (McClain et al., 2018), indicating that the accumulation of circulating MNP in the brain of $\mathrm{LCH}$ patients may contribute to subsequent neurodegeneration in these patients. Prior results have shown that senescence can lead to cognition-associated neuronal loss in mice (Bussian et al., 2018). Here we show that circulating MNP that accumulate in LCH-ND lesions also express the senescent marker $\mathrm{p} 16^{\text {INK4a }}$ suggesting that senescent cells may drive LCH-ND in patients with LCH. These results suggest senolytics may help improve this grueling LCH complication.

Systemic LCH remains a difficult to treat condition that can require the use of high-dose chemotherapy followed by allogenic BM transplantation (reviewed in (Allen et al., 2015; Donadieu et al., 2015)). BRAF or MEK inhibition therapies can improve clinical outcome, although this approach is not curative in most cases as most patients recur upon treatment interruption (Cohen Aubart et al., 2017; Diamond et al., 2019; Eckstein et al., 2019). Our study strongly suggests that mTOR inhibitors and senolytics may provide a critical alternative to cytotoxic chemotherapy, BM transplant and chronic MAPK pathway inhibition for the treatment of LCH patients including patients with LCH-ND.

Altogether these results reveal the contribution of BRAFV600E-driven senescence to $\mathrm{LCH}$ pathophysiology and identify senescent cells as an important target for the treatment of systemic $\mathrm{LCH}$.

\section{Declarations}

Acknowledgements: We would like to thank the Biorepository and Pathology Core and the Flow Cytometry Core Facilities at the Icahn School of Medicine at Mount Sinai for their technical expertise.

We also thank Karen Phaik Har Lim, Tsz-Kwong Man, Thomas Burke and Brooks Scull for their help with the generation of microarray sequencing. We would like to thank Dr. Julia Kofler for kindly providing LCHND pictures and performing immunostainings. We thank Guray Akturk, Leanna Troncosa, Jerome Martin, John Grout and Jenielle Jobson for their help.

We would like to thank Mr. Chris Woods, Image application specialist, Cincinnati Children;'s Hospital Medical Center, for figure preparation for human studies (Fig 4G) and Dr. Julia Kofler, MD UPMC Division 
of Neuropathology for creation of supplementary figure 4E.

Camille Bigenwald has received fellowships from Fondation pour la Recherche Médicale (FDM20170638478), from I'Institut Servier and from Assistance Publique Hôpitaux de Paris (Année Recherche). CMW is supported by the Swiss National Science Foundation (SNSF PostDoc Mobility Fellowship P400PM_186740) and by the Swiss Cancer League (Grant for Bursaries BIL KFS 4724-022019). We would like to thank the research coordinators of Histio/Lymphoma team at Texas Children's Cancer Center for their help in patient sample collection. The TXCH Histiocytosis Program is supported by a research grant from the HistioCure Foundation. This work was supported by the Department of Defense through the Peer Reviewed Cancer Research Program under Award No. W81XWH-19-1-0167 (R.C.).

Author contributions: C.B., J.L.B., C.M.W., R.C., S.T.C., A.T., R.M., H.A., J.J., I.L., M.C.A., M.J., J.A.G., J.P., H.A., J.P designed and carried out experiments. A.B., P.I.P., A.L., S.G., K.L.M., J.P., C.A. and M.M. supervised experiments and analyzed and interpreted data. C.B., C.A. and M.M. drafted the manuscript. C.A. and M.M. designed the study, supervised experimental data collection, and coordinated integration of collaboration between all participating laboratories. All authors critically reviewed and edited the final version of the manuscript.

\section{References}

Allen, C.E., Li, L., Peters, T.L., Leung, H. c. E., Yu, A., Man, T.K., Gurusiddappa, S., Phillips, M.T., Hicks, M.J., Gaikwad, A., et al. (2010). Cell-Specific Gene Expression in Langerhans Cell Histiocytosis Lesions Reveals a Distinct Profile Compared with Epidermal Langerhans Cells. J. Immunol. 184, 4557-4567.

Allen, C.E., Ladisch, S., and McClain, K.L. (2015). How I treat Langerhans cell histiocytosis. Blood 126, 26-35.

Allen, C.E., Merad, M., and McClain, K.L. (2018). Langerhans-Cell Histiocytosis. N. Engl. J. Med. 379, 856868.

Baccarini, A., Chauhan, H., Gardner, T.J., Jayaprakash, A.D., Sachidanandam, R., and Brown, B.D. (2011). Kinetic analysis reveals the fate of a microRNA following target regulation in mammalian cells. Curr. Biol. $21,369-376$.

Badalian-Very, G., Vergilio, J.-A., Degar, B.A., MacConaill, L.E., Brandner, B., Calicchio, M.L., Kuo, F.C., Ligon, A.H., Stevenson, K.E., Kehoe, S.M., et al. (2010). Recurrent BRAF mutations in Langerhans cell histiocytosis. Blood 116, 1919-1923.

Baker, D.J., Wijshake, T., Tchkonia, T., LeBrasseur, N.K., Childs, B.G., van de Sluis, B., Kirkland, J.L., and van Deursen, J.M. (2011). Clearance of p16Ink4a-positive senescent cells delays ageing-associated disorders. Nature 479, 232-236. 
Berres, M.-L., Lim, K.P.H., Peters, T., Price, J., Takizawa, H., Salmon, H., Idoyaga, J., Ruzo, A., Lupo, P.J., Hicks, M.J., et al. (2015). BRAF-V600E expression in precursor versus differentiated dendritic cells defines clinically distinct LCH risk groups. J. Exp. Med. 212, 281.

Bussian, T.J., Aziz, A., Meyer, C.F., Swenson, B.L., van Deursen, J.M., and Baker, D.J. (2018). Clearance of senescent glial cells prevents tau-dependent pathology and cognitive decline. Nature 562, 578-582.

Chakraborty, R., Hampton, O.A., Shen, X., Simko, S.S., Shih, A., Abhyankar, H., Lim, K.P.H., Trevinon, L., Dewal, N., Muzny, D.M., et al. (2014). Mutually exclusive recurrent somatic mutations in MAP2K1 and BRAF support a central role for ERK activation in LCH pathogenesis. Blood 124, 3007-3015.

Chakraborty, R., Burke, T.M., Hampton, O.A., Zinn, D.J., Lim, K.P.H., Abhyankar, H., Scull, B., Kumar, V., Kakkar, N., Wheeler, D.A., et al. (2016). Alternative genetic mechanisms of BRAF activation in Langerhans cell histiocytosis. Blood 128, 2533-2537.

Chang, J., Wang, Y., Shao, L., Laberge, R.-M., Demaria, M., Campisi, J., Janakiraman, K., Sharpless, N.E., Ding, S., Feng, W., et al. (2016). Clearance of senescent cells by ABT263 rejuvenates aged hematopoietic stem cells in mice. Nat. Med. 22, 78-83.

Cohen Aubart, F., Emile, J.-F., Carrat, F., Charlotte, F., Benameur, N., Donadieu, J., Maksud, P., Idbaih, A., Barete, S., Hoang-Xuan, K., et al. (2017). Targeted therapies in 54 patients with Erdheim-Chester disease, including follow-up after interruption (the LOVE study). Blood 130,1377-1380.

Dankort, D., Filenova, E., Collado, M., Serrano, M., Jones, K., and McMahon, M. (2007). A new mouse model to explore the initiation, progression, and therapy of BRAFV600E-induced lung tumors. Genes Dev. $21,379-384$.

Diamond, E.L., Durham, B.H., Ulaner, G.A., Drill, E., Buthorn, J., Ki, M., Bitner, L., Cho, H., Young, R.J., Francis, J.H., et al. (2019). Efficacy of MEK inhibition in patients with histiocytic neoplasms. Nature.

Donadieu, J., Bernard, F., van Noesel, M., Barkaoui, M., Bardet, O., Mura, R., Arico, M., Piguet, C., Gandemer, V., Armari Alla, C., et al. (2015). Cladribine and cytarabine in refractory multisystem Langerhans cell histiocytosis: results of an international phase 2 study. Blood 126, 1415-1423.

Durham, B.H., Roos-Weil, D., Baillou, C., Cohen-Aubart, F., Yoshimi, A., Miyara, M., Papo, M., HéliasRodzewicz, Z., Terrones, N., Ozkaya, N., et al. (2017). Functional evidence for derivation of systemic histiocytic neoplasms from hematopoietic stem/progenitor cells. Blood 130,176-180.

Eckstein, O.S., Visser, J., Rodriguez-Galindo, C., and Allen, C.E. (2019). Clinical responses and persistent BRAF V600E + blood cells in children with LCH treated with MAPK pathway inhibition. Blood blood-201810-878363.

Göthert, J.R., Gustin, S.E., Hall, M.A., Green, A.R., Göttgens, B., Izon, D.J., and Begley, C.G. (2005). In vivo fate-tracing studies using the $\mathrm{Scl}$ stem cell enhancer: embryonic hematopoietic stem cells significantly 
contribute to adult hematopoiesis. Blood 105, 2724-2732.

Haroche, J., Cohen-Aubart, F., Emile, J.-F., Donadieu, J., and Amoura, Z. (2017). Neurodegeneration in histiocytoses might start in utero. Lancet. Neurol. 16, 953-954.

Hernandez-Segura, A., Nehme, J., and Demaria, M. (2018). Hallmarks of Cellular Senescence. Trends Cell Biol. 28, 436-453.

Herranz, N., Gallage, S., Mellone, M., Wuestefeld, T., Klotz, S., Hanley, C.J., Raguz, S., Acosta, J.C., Innes, A.J., Banito, A., et al. (2015). mTOR regulates MAPKAPK2 translation to control the senescenceassociated secretory phenotype. Nat. Cell Biol. 17, 1205-1217.

Hogstad, B., Berres, M.-L., Chakraborty, R., Tang, J., Bigenwald, C., Serasinghe, M., Lim, K.P.H., Lin, H., Man, T.-K., Remark, R., et al. (2018). RAF/MEK/extracellular signal-related kinase pathway suppresses dendritic cell migration and traps dendritic cells in Langerhans cell histiocytosis lesions. J. Exp. Med. 215, 319336.

Jenson, H.B., McClain, K.L., Leach, C.T., Deng, J.H., and Gao, S.J. (2000). Evaluation of human herpesvirus type 8 infection in childhood langerhans cell histiocytosis. Am. J. Hematol. 64, 237-241.

Jeon, O.H., Kim, C., Laberge, R.-M., Demaria, M., Rathod, S., Vasserot, A.P., Chung, J.W., Kim, D.H., Poon, Y., David, N., et al. (2017). Local clearance of senescent cells attenuates the development of post- traumatic osteoarthritis and creates a pro-regenerative environment. Nat. Med. 23, 775-781.

Kuilman, T., Michaloglou, C., Vredeveld, L.C.W., Douma, S., van Doorn, R., Desmet, C.J., Aarden, L.A., Mooi, W.J., and Peeper, D.S. (2008). Oncogene-Induced Senescence Relayed by an Interleukin- Dependent Inflammatory Network. Cell 133, 1019-1031.

Laberge, R.-M., Sun, Y., Orjalo, A. V, Patil, C.K., Freund, A., Zhou, L., Curran, S.C., Davalos, A.R., Wilson-Edell, K.A., Liu, S., et al. (2015). MTOR regulates the pro-tumorigenic senescence-associated secretory phenotype by promoting IL1A translation. Nat. Cell Biol. 17, 1049-1061.

Lee, J., Zhou, Y.J., Ma, W., Zhang, W., Aljoufi, A., Luh, T., Lucero, K., Liang, D., Thomsen, M., Bhagat, G., et al. (2017). Lineage specification of human dendritic cells is marked by IRF8 expression in hematopoietic stem cells and multipotent progenitors. Nat. Immunol. 18, 877-888.

Lim, K.P.H., Milne, P., Poidinger, M., Duan, K., Lin, H., McGovern, N., Abhyankar, H., Zinn, D., Burke, T.M., Eckstein, O.S., et al. (2020). Circulating CD1c+ myeloid dendritic cells are potential precursors to $\mathrm{LCH}$ lesion CD1a+CD207+ cells. Blood Adv. 4, 87-99.

Mass, E., Jacome-Galarza, C.E., Blank, T., Lazarov, T., Durham, B.H., Ozkaya, N., Pastore, A., Schwabenland, M., Chung, Y.R., Rosenblum, M.K., et al. (2017). A somatic mutation in erythro-myeloid progenitors causes neurodegenerative disease. Nature 549, 389-393. 
McClain, K., Jin, H., Gresik, V., and Favara, B. (1994). Langerhans cell histiocytosis: lack of a viral etiology. Am. J. Hematol. 47, 16-20.

McClain, K.L., Picarsic, J., Chakraborty, R., Zinn, D., Lin, H., Abhyankar, H., Scull, B., Shih, A., Lim, K.P.H., Eckstein, O., et al. (2018). CNS Langerhans cell histiocytosis: Common hematopoietic origin for LCHassociated neurodegeneration and mass lesions. Cancer 124, 2607-2620.

Merad, M., Ginhoux, F., and Collin, M. (2008). Origin, homeostasis and function of Langerhans cells and other langerin-expressing dendritic cells. Nat. Rev. Immunol. 8, 935-947.

Merad, M., Sathe, P., Helft, J., Miller, J., and Mortha, A. (2013). The dendritic cell lineage: ontogeny and function of dendritic cells and their subsets in the steady state and the inflamed setting. Annu. Rev. Immunol. 31, 563-604.

Michaloglou, C., Vredeveld, L.C.W., Soengas, M.S., Denoyelle, C., Kuilman, T., van der Horst, C.M.A.M., Majoor, D.M., Shay, J.W., Mooi, W.J., and Peeper, D.S. (2005). BRAFE600-associated senescence-like cell cycle arrest of human naevi. Nature $436,720-724$.

Milne, P., Bigley, V., Bacon, C.M., Néel, A., McGovern, N., Bomken, S., Haniffa, M., Diamond, E.L., Durham, B.H., Visser, J., et al. (2017). Hematopoietic origin of Langerhans cell histiocytosis and Erdheim- Chester disease in adults. Blood 130, 167-175.

Montecino-Rodriguez, E., Berent-Maoz, B., and Dorshkind, K. (2013). Causes, consequences, and reversal of immune system aging. J. Clin. Invest. 123, 958-965.

Muñoz-Espín, D., and Serrano, M. (2014). Cellular senescence: from physiology to pathology. Nat. Rev. Mol. Cell Biol. 15, 482-496.

Picarsic, J., and Jaffe, R. (2015). Nosology and Pathology of Langerhans Cell Histiocytosis. Hematol. Oncol. Clin. North Am. 29, 799-823.

Remark, R., Merghoub, T., Grabe, N., Litjens, G., Damotte, D., Wolchok, J.D., Merad, M., and Gnjatic, S. (2016). In-depth tissue profiling using multiplexed immunohistochemical consecutive staining on single slide. Sci. Immunol. 1.

Stålemark, H., Laurencikas, E., Karis, J., Gavhed, D., Fadeel, B., and Henter, J.-I. (2008). Incidence of Langerhans cell histiocytosis in children: a population-based study. Pediatr. Blood Cancer 51, 76-81.

Xerri, L., Adélaïde, J., Popovici, C., Garnier, S., Guille, A., Mescam-Mancini, L., Laurent, C., Brousset, P., Coze, C., Michel, G., et al. (2018). CDKN2A/B Deletion and Double-hit Mutations of the MAPK Pathway Underlie the Aggressive Behavior of Langerhans Cell Tumors. Am. J. Surg. Pathol. 42, 150-159. 
Yeh, E.A., Greenberg, J., Abla, O., Longoni, G., Diamond, E., Hermiston, M., Tran, B., Rodriguez- Galindo, C., Allen, C.E., McClain, K.L., et al. (2018). Evaluation and treatment of Langerhans cell histiocytosis patients with central nervous system abnormalities: Current views and new vistas. Pediatr. Blood Cancer 65, e26784.

\section{Materials And Methods}

\section{Animal experiments}

All animal experiments performed in this study were approved by the Institutional Animal Care and Use Committee at the Icahn School of Medicine at Mount Sinai. BRAFV600E ${ }^{\mathrm{Scl}+}$, $B R A F \mathrm{wt}^{\mathrm{Scl}+}, B R A F \mathrm{~V} 600 \mathrm{E}^{\mathrm{Scl}-}$, and $B R A F \mathrm{wt}^{\mathrm{Scl}-}$ mice were created by crossing $B R A F \mathrm{~V} 600 \mathrm{E}^{\mathrm{ca} / \mathrm{ca}}$ mice (provided by M.W. Bosenberg, Yale University, New Haven, CT (Dankort et al., 2007)) with mice expressing an inducible cre recombinase under the control of the Scl promotor (provided by Yuko Fujiwara, Harvard Medical School, Howard Hughes Medical Institute, Boston, MA (Göthert et al., 2005)). BRAFV600E $\mathrm{E}^{\mathrm{ca} /-} \mathrm{X} \mathrm{Scl}^{\mathrm{cre}-\mathrm{ER}}$ were then crossed with Rosa26 ${ }^{\mathrm{YFP} / \mathrm{YFP}}$ mice (C57BL/6 background; The Jackson Laboratory). To induce the cre recombinase, $B R A F V 600 \mathrm{E}^{\mathrm{Scl}+}, B R A F \mathrm{wt}^{\mathrm{Scl}+}$, or $B R A F \mathrm{~V} 600 \mathrm{E}^{\mathrm{Scl}-}$ control littermates were injected intra-peritoneally with tamoxifen for 5 consecutive days (5 mg, day 1 ; $2 \mathrm{mg}$, days 2 , and 3 ; 1 mg, days 4 and 5). All animals were housed under specific pathogen-free conditions and sacrificed at the indicated time points. All experiments were controlled using cre-positive littermates negative for the $B R A F V 600 \mathrm{E}$ construct or littermates negative for the cre recombinase transgene construct. $B R A F V 600 \mathrm{E}$ or $B R A F \mathrm{wt}$ chimeras were generated by transplantation of 1 to 3 million whole BM cells flushed from the femurs of 8 weeks old $B R A F V 600 \mathrm{E}^{\mathrm{Scl}+}$ or $B R A F \mathrm{Wt}^{\mathrm{Scl}+}$ mice following the tamoxifen injections, into lethally irradiated (650 cGy X 2) CD45.1 mouse aged 8-12 weeks (C57BL/6 background; Charles River Laboratory). Mice were kept on Sulfamethoxazole / Trimethoprim (STI Pharma) for 3 weeks. Mice were allowed to recover for 2 weeks after transplantation before initiation of drug treatments.

$B R A F V 600 \mathrm{E}^{\mathrm{Scl}+} \mathrm{ATTAC}^{+}$and $B R A F \mathrm{wt} \mathrm{Scl}^{\mathrm{S}} \mathrm{ATTAC}^{+}$mice were generated by crossing the litters from $B R A F V 600 E^{\mathrm{ca} / c a}$ mice and $\mathrm{Scl}^{\text {cre-ER }}$ with $\mathrm{ATTAC}^{+/-}$mice (kindly provided by Lorenzo Galuzzi, Weill Cornell Medical College University, New York, NY). The cre recombinase was induced as described earlier.

NOD scid gamma (NSG) mice were purchased from the Jackson Laboratory (BALB/c background) and were housed under specific pathogen-free conditions. Humanized mice were generated by transplanting 8 weeks old NSG mice sub-lethally irradiated with 250 cGy with 200,000 human CD34+ ${ }^{+}$cells previously transduced for 16 to 24 hours with the BRAFV600E or NGFR lentiviral vector. 


\section{Human specimens}

Human tissues used in these studies were collected, stored, and processed according to protocols approved by the Baylor College of Medicine Institutional Review Board. Healthy control tissues were obtained from the Biorepository and Pathology CoRE facility (Dr. Donovan) at Mount Sinai School of Medicine. Cord blood was obtained from the New York Blood Center, National Cord Blood Program.

\section{Lentiviral vector construction}

BRAFV600E and NGFR transgenes were cloned into lentiviral expression vectors upstream of a 2A peptide linked to GFP for in vivo and in vitro analysis of transduced cells using standard cloning procedures. Briefly, PCR products were amplified from pcDNA3 (provided by Poulikos Poulikakos) (plasmid) using High Fidelity Taq polymerase. PCR products were purified using the QIAquick PCR purification Kit (Qiagen), and restriction enzymes SalI and XbaI were used to digest the vector and PCR products. PCR products were ligated with the expression vector using NEB Quick Ligase and the plasmid was verified with Sanger Sequencing.

\section{Lentiviral vector production and titration}

Lentiviral vectors were produced as previously described (Baccarini et al., 2011). Briefly, 293T cells were seeded approximately 24 hours before transfection in a $15 \mathrm{~cm}$ plate and incubated at $37^{\circ} \mathrm{C}$ with $5 \% \mathrm{CO}_{2}$. The following day, the cells were transfected with a third generation packaging system (pVSV, pMDLg/pRRE, pRSV-REV) and the appropriate transfer plasmid using calcium phosphate. The media was changed 14 hours later. Another 30 hours later, the supernatant containing the vector was harvested, passed through a $0.22 \mu \mathrm{m}$ filter and ultracentrifuged (20,000 rpm for 2 hours) to concentrate the vector $300-500$-fold. The vector particles were resuspended in sterile PBS, aliquoted and stored at $-80^{\circ} \mathrm{C}$. Vector titration was performed on 293T cells using the limiting dilution method.

\section{Cord blood processing and transduction}

Mononuclear cells from cord blood were isolated via a Ficoll-Paque PLUS (GE Healthcare) gradient. Mononuclear cells were washed and resuspended in FACS buffer (PBS without $\mathrm{Ca}^{2+}$ 
and $\mathrm{Mg}^{2+}$ supplemented with $2 \%$ heat inactivated FBS and 5mM EDTA). CD34 ${ }^{+}$cells were purified using a CD34 MicroBead kit Human from Miltenyi Biotec (130-100-453).

CD34 ${ }^{+}$human hematopoietic progenitor cells were resuspended at a concentration of 1 million cells/mL in Stemspan media SFEM II (StemCell Technologies, 09605) supplemented with $100 \mathrm{ng} / \mathrm{mL}$ SCF, 100ng/mL FLT3-L and 50ng/mL TPO (so called stem-cell media). 200,000 cells were plated in a 48 well plate and $5 \mu \mathrm{L}$ of lentiviral construct (either BRAFV600E or NGFR) was added to the media for a $\mathrm{MOI}=50$. The cells were incubated at $37^{\circ} \mathrm{C}$ and $5 \% \mathrm{CO}_{2}$. Supplemented Stemspan media was added 24 hours after the initiation of transduction and cells were kept in culture for up to 14 days. GFP-transduced cells were analyzed for myeloid and lymphoid surface marker expression (see antibody list) starting two days after the transduction.

\section{Flow cytometry and FACS}

Adult skin (from the ears), lung, liver, spleen, and femurs were dissected from mice at the age of 12-16 weeks. Adult skin was first incubated overnight at $4^{\circ}$ in dispase II solution (Roche) $(2.5 \mathrm{mg} / \mathrm{mL}$ in PBS) with the dermal side facing down. The dermis was separated mechanically from the epidermis and both tissues were digested in a solution of collagenase D (Roche) (1 $\mathrm{mg} / \mathrm{mL}$ ) and DNase I (Roche) $\left(1 \mathrm{mg} / \mathrm{mL}\right.$ ) in RPMI (Corning) $+10 \%$ FBS for one hour at $37^{\circ} \mathrm{C}$. After digestion, the dermis and epidermis were homogenized using a 18G needle. The cell suspension was filtered through a $70 \mu \mathrm{m}$ cell strainer into a flow cytometry tube.

For the spleen and the lung, tissues were enzymatically digested in a solution of collagenase D (Roche) $(1 \mathrm{mg} / \mathrm{mL})$ and DNase I (Roche) $(1 \mathrm{mg} / \mathrm{mL})$ in HBSS (Corning) for 30 minutes at $37^{\circ} \mathrm{C}$, followed by mechanical trituration with an 18G blunt tipped syringe and filtration through a $70 \mu \mathrm{m}$ filter.

Single cell suspensions from liver were obtained after digestion with collagenase IV (C5138, Sigma) in HBSS (Corning) at $37^{\circ} \mathrm{C}$ for 45 minutes. Nonparenchymal cells were enriched by centrifugation in 35\% Percoll (17-0891-01, GE Healthcare) for 30 min at 1,300 rcf.

BM single cell suspensions were obtained after flushing out the BM from the femur using a 27G needle and then were incubated with ACK lysis buffer (420301, BioLegend) for 3 minutes at room temperature. Blood was drawn from the liver sinus and treated twice with ACK lysis buffer for 5 minutes at room temperature.

For flow cytometry, cells were stained in FACS buffer (PBS without $\mathrm{Ca}^{2+}$ and $\mathrm{Mg}^{2+}$ supplemented with $2 \%$ heat-inactivated FBS and $5 \mathrm{mM}$ EDTA) with flow cytometry monoclonal antibodies for 20 minutes at $4^{\circ} \mathrm{C}$. 
Murine hematopoietic progenitor cells were sorted as singlets of $\mathrm{DAPI}^{-}$lineage ${ }^{-}$c-kit ${ }^{+} \mathrm{Sca1}^{-}$, and murine $\mathrm{LSK}^{+}$cells were sorted as singlets $\mathrm{DAPI}^{-}$lineage ${ }^{-} \mathrm{c}-\mathrm{kit}^{+} \mathrm{Sca}^{+}{ }^{+}$. Human transduced HPC were sorted as DAPI', GFP ${ }^{+}$, or GFP- singlets.

Flow cytometry was performed using a Fortessa analyzer (BD) and FACS sorting was performed using a FACS Aria II (BD) or LSRII (BD). Flow cytometry data analysis was performed using FlowJo (TreeStar) software. 


\begin{tabular}{|c|c|c|c|c|}
\hline Markers & Reactivity & Clone & Company & Dilution \\
\hline CD16/32 & mouse & 93 & eBioscience & $1 / 200$ \\
\hline Sca1 & mouse & D7 & eBioscience & $1 / 200$ \\
\hline c-kit & mouse & 2B8 & eBioscience & $1 / 200$ \\
\hline FLT3L & mouse & $\mathrm{A} 2 \mathrm{~F} 10$ & eBioscience & $1 / 100$ \\
\hline CD34 & mouse & RAM34 & eBioscience & $1 / 100$ \\
\hline CD11b & mouse & M1/70 & eBioscience & $1 / 100$ \\
\hline Ter119 & mouse & TER-119 & eBioscience & $1 / 200$ \\
\hline Gr1 & mouse & RB6-8C5 & eBioscience & $1 / 200$ \\
\hline B220 & mouse & RA3-6B2 & eBioscience & $1 / 200$ \\
\hline CD115 & mouse & AFS98 & eBioscience & $1 / 200$ \\
\hline CD45 & mouse & 30-F11 & Biolegend & $1 / 200$ \\
\hline Ly6G & mouse & $1 \mathrm{~A} 8$ & Biolegend & $1 / 200$ \\
\hline MHC II & mouse & M5/114.15.2 & eBioscience & $1 / 200$ \\
\hline CD11c & mouse & N418 & Invitrogen & $1 / 200$ \\
\hline Ly6C & mouse & A2-21 & eBioscience & $1 / 200$ \\
\hline $\mathrm{F} 4 / 80$ & mouse & BM8 & Biolegend & $1 / 200$ \\
\hline Siglec F & mouse & E50:2440 & BD bioscience & $1 / 200$ \\
\hline CD24 & mouse & M1/69 & BD bioscience & $1 / 200$ \\
\hline CD103 & mouse & $2 \mathrm{E} 7$ & Biolegend & $1 / 200$ \\
\hline EpCAM & mouse & G8.8 & eBioscience & $1 / 200$ \\
\hline CD4 & mouse & RM4.5 & eBioscience & $1 / 200$ \\
\hline CD8 & mouse & $5 \mathrm{H} 10$ & Invitrogen & $1 / 200$ \\
\hline CD3 & mouse & $145-2 \mathrm{C} 11$ & BD bioscience & $1 / 200$ \\
\hline NK1.1 & mouse & PK136 & eBioscience & $1 / 200$ \\
\hline CD45 & human & $2 \mathrm{D} 1$ & eBioscience & $1 / 200$ \\
\hline CD34 & human & 581 & Biolegend & $5 / 100$ \\
\hline CD38 & human & HIT2 & BD bioscience & $3 / 100$ \\
\hline CD123= IL3Ra 6 & human & $6 \mathrm{H} 6$ & Biolegend & $1 / 100$ \\
\hline CD11c & human & B-ly6 & BD Horizon & $1 / 100$ \\
\hline CD1a & human & HI149 & Biolegend & $1 / 100$ \\
\hline CD14 & human & MHCD1405 & Invitrogen & $1 / 100$ \\
\hline CD207 & human & IM3577 & Beckman Coulter & $1 / 100$ \\
\hline
\end{tabular}

\section{Multiplexed Immunohistochemical Consecutive Staining on a Single Slide}


Tissues were fixed in $4 \%$ formaldehyde for 24 hours and embedded in paraffin. Five mm-thick formalin-fixed paraffin-embedded (FFPE) tissue sections on glass slides were baked at $37^{\circ} \mathrm{C}$ overnight, deparaffinized in xylene, and rehydrated in decreasing concentrations of ethanol. Then, tissue sections were incubated in retrieval solution (pH6 or 9) for antigen retrieval at $95^{\circ} \mathrm{C}$ for 30 minutes. Tissue sections were incubated in $3 \%$ hydrogen peroxide and in serumfree protein block solution (Dako, X0909) before adding the primary antibody for 1 hour at room temperature. After signal amplification using EnVison + System- HRP labelled Polymer anti-mouse (Dako, K4001) or anti-rabbit (Dako, K4003), chromogenic revelation was performed using 3-amino-9-ethylcarbazole (AEC, Vector Laboratories SK4200). Slides were counterstained with hematoxylin, mounted with a glycerol-based mounting medium (Dako, C0563) and scanned for digital imaging (Hamamatsu NanoZoomer S60 Whole Slide Scanner). Then, the same slides were successively stained as described (Remark et al., 2016). Primary antibodies were:

\begin{tabular}{|c|c|c|c|c|c|c|}
\hline er & Reactivity & Reference & Clone & $\begin{array}{l}\text { Antigen } \\
\text { retrieval }\end{array}$ & Dilution & Incubation \\
\hline erin & Human & Novocastra & $12 \mathrm{D} 6$ & pH9 & $1 / 50$ & $\begin{array}{l}1 \text { hour at } \\
\text { RT }\end{array}$ \\
\hline \multirow[t]{2}{*}{ l } & Human & Dako & O10 & $\mathrm{pH} 6$ & $1 / 50$ & $\begin{array}{l}1 \text { hour at } \\
\text { RT }\end{array}$ \\
\hline & Human & Ventana & $30-09$ & pH9 & RTU & $\begin{array}{l}1 \text { hour at } \\
\text { RT }\end{array}$ \\
\hline \multirow[t]{2}{*}{17} & Mouse & eBioscience & eBioRMUL.2 & $\mathrm{pH} 9$ & $1 / 200$ & $\begin{array}{l}\text { overnight } \\
\text { at } 4^{\circ} \mathrm{C}\end{array}$ \\
\hline & Mouse & Bethyl & IHC-00375 & $\mathrm{pH} 9$ & $1 / 250$ & $\begin{array}{l}\text { Overnight } \\
\text { at } 4^{\circ} \mathrm{C}\end{array}$ \\
\hline JK4a & Human & $\begin{array}{lr}\text { Santa Cruz } \\
\text { Biotechnology }\end{array}$ & Sc-759 & $\mathrm{pH} 9$ & $1 / 50$ & $\begin{array}{l}1 \text { hour at } \\
\text { RT }\end{array}$ \\
\hline JK4a & Human & Ventana & BioHistomarker & $\mathrm{CC} 1$ & $\mathrm{~N} / \mathrm{A}$ & \\
\hline$i$ & Human & Leica & PWS44 & CC1 & $1 / 100$ & \\
\hline 3 & Human & Novocastra & 10D6 & CC1 & $1 / 200$ & \\
\hline$=$ & Human & Abcam & 7 & CC1 & $1 / 10$ & \\
\hline$\overline{7 V 600 E}$ & Human & Ventana & VE1 & CC1 & $1 / 50$ & \\
\hline 12 & Human & Sigma & $\mathrm{N} / \mathrm{A}$ & $\begin{array}{l}\text { Target } \\
\text { Retrieval } \\
\text { Solution } \\
(\text { Dako) } \\
\end{array}$ & $1 / 1000$ & \\
\hline
\end{tabular}


RTU: ready to use

The images were analyzed (automatic analysis) using the QuPath software (https://qupath.github.io/).

\section{Senescence-associated $\beta$ galactosidase staining}

Cells or frozen tissues were stained for SAbGal using the Senescence Detection Kit (BioVision, K320-250) according to the manufacturer's instructions. Senescent cells were identified as blue- stained cells in light microscopy. Images were taken using a Hamamatsu NanoZoomer S60 Whole Slide Scanner. The images were analyzed using the QuPath software (https://qupath.github.io/).

\section{Western Blot}

Cells were lysed with lysis buffer (50mM Tris pH 7.5, 1\% NP40, 150mM NaCl, 10\% Glycerol, $1 \mathrm{mM}$ EDTA, supplemented with protease inhibitor cocktail tablets, Roche). After 5 min incubation on ice, lysates were centrifuged at 15,000 rpm for $10 \mathrm{~min}$ and supernatants were collected. Protein concentration was quantified using BCA (Pierce). Proteins were separated by NuPAGE, 4-12\% Bis-Tris Gel (Novex) and transferred to nitrocellulose membranes (10600006, Amersham) according to standard protocols. Membranes were immunoblotted overnight with primary antibodies against pERK (4370L, Cell Signaling), BRAF (9002, Santa Cruz) and $\beta$-Actin (5125S, Cell Signaling) followed by secondary anti-rabbit IgG antibody (7074S, Cell Signaling). Chemiluminescent signals were detected on X-ray film.

\section{Methylcellulose assays}

To determine the differentiation potential of murine progenitors, femurs from $B R A F V 600 E^{S c l+}$ or $B R A F \mathrm{wt}^{\mathrm{Scl+}}$ control littermates were harvested. Lineage negative BM cells were obtained with a lineage cell depletion kit MACS (Miltenyi Biotec, 130-090-858). 1000 lineage negative $\mathrm{BM}$ cells (or sorted lineage negative Rosa ${ }^{\mathrm{YFP}} \mathrm{BM}$ cells depending on the experiment) were resuspended in Iscove's modified Dulbecco's medium (IMDM, GIBCO) supplemented with 2\% FBS, plated in $1 \mathrm{~mL}$ of methylcellulose medium (Methocult M3434, StemCell Technologies) and kept in culture for 14 days. The number and type of colony-forming unit were assessed at day 14. 
To determine the differentiation potential of human progenitors, 500 transduced CD34 $4^{+}$HPC were sorted according to their GFP expression three days after transduction, resuspended in Iscove's modified Dulbecco's medium (IMDM, GIBCO) supplemented with $2 \%$ FBS, and plated in $1 \mathrm{~mL}$ of methylcellulose medium (Methocult H4434, StemCell Technologies) for 14 days. The number and type of colony-forming unit were assessed at day 14.

\section{Gene expression profile using micro-arrays and RNA sequencing}

100,000 human transduced HPC were sorted according to their GFP expression directly into Arcturus PicoPure Extraction Buffer (Applied Biosystems, 12317-03) seven days after transduction with $B R A F V 600 \mathrm{E}$ or NGFR lentiviral construct. Total RNA was processed from the sorted cells, according to the PicoPure RNA Isolation Kit protocol (Molecular Devices). RNA concentration and quality were verified using the 6000 Pico Chip (Agilent, Palo Alto, CA) at the Baylor College of Medicine Microarray Facility. cDNA amplification was performed with the WTOvation Pico System, according to the manufacturer's protocol (NuGen, San Carlos, CA). Fragmented and biotinylated cDNA samples for the gene chip studies were generated using the FL-Ovation cDNA Biotin Module v2 (NuGen).

For figure 4B, total RNA was isolated from sorted subpopulations from peripheral blood and lesion specimens according to the Arcturus PicoPure RNA Isolation Kit protocol (Applied Biosystems). RNA quality was verified using the Pico Chip at Baylor College of Medicine Microarray Facility (all RIN>6). cDNA amplification was performed using the Ovation Pico WTA V2 System according to the manufacturer's protocol (Nugen, San Carlos, CA). Fragmented and biotinylated cDNA was hybridized to GeneChipTM Human Transcriptome Array 2.0 according to the manufacturer's procedures (Affymetrix, Waltham, MA). Raw data from all samples were normalized using the SST-RMA algorithm implemented in the Affymetrix Expression Console. Differentially expressed genes (DEGs) were identified using BRB-ArrayTools v4.5 (V4.5, Biometric Research Branch, NCI, MD, USA) with a multivariate permutation test with a confidence level of false discovery rate assessment at $80 \%$ and the maximum allowed proportion of false-positive proteins at 0.1 .

Human $\mathrm{CD} 4^{+} \mathrm{BM}$ cells from $\mathrm{LCH}$ patients were sorted directly into TRIzol LS Reagent (ambion by life technologies, ref \# 10296028) and stored at $-80^{\circ} \mathrm{C}$. RNA was extracted according to the RNeasy Mini Kit protocol (Qiagen). 1 ng of RNA was converted to cDNA using the SMART- Seq v4 Ultra Low Input RNA Kit (Clontech). RNA-seq libraries were prepared using the Low Input Library Prep Kit v2 (Clontech). Sequencing was performed using the Illumina NextSeq-500 system. Transcript abundance was quantified with the Ensembl GRCh38 cDNA reference using Kallisto version 0.43.0. 


\section{Quantitative PCR}

Conventional reverse transcription was performed using the RNA to cDNA EcoDry Premix (639548, Takara Bio) in accordance with the manufacturer's instructions. Q-PCR was performed on a CFX384 Touch Real-Time PCR detection system (Bio Rad) using EXPRESS SYBR GreenER master mix (11784200, Invitrogen) as follows: one cycle at $95^{\circ} \mathrm{C}(10 \mathrm{~min}), 40$ cycles of $95^{\circ} \mathrm{C}(15 \mathrm{~s})$ and $58^{\circ} \mathrm{C}(1 \mathrm{~min})$. Expression of actin was used to normalize expression. The average threshold cycle number (CRtR) for each tested mRNA was used to quantify the relative expression: $2^{\wedge}[\mathrm{Ct}(\operatorname{actin})-\mathrm{Ct}(C D K N 2 A)]$. Primers are listed below:

\begin{tabular}{|l|l|}
\hline Gene & Sequence \\
\hline 5'-actin & CTAAGGCCAACCGTGAAA \\
\hline 3'-actin & ACCAGAGGCATACAGGGA \\
\hline 5'- CDKN2A & CCCAACGCCCCGAACT \\
\hline 3'- CDKN2A & GCAGAAGAGCTGCTACGTGAA \\
\hline 5'-IL-1a & CCATAACCCATGATCTGGAAGAGAC \\
\hline 3'-IL-1a & GTCCACATCCTGATATATAGTTTG \\
\hline 5' - IL-1b & TGGCAACTGTTCCTGAAC \\
\hline 3'-IL-1b & GGGTCCGTCAACTTCAAA \\
\hline 5'-IL-6 & GCTACCAAACTGGATATA \\
\hline 3'-IL-6 & CCAGGTAGCTATGGTACT \\
\hline 5'- MMP13 & GGAGCCCTGATGTTTCCCAT \\
\hline 3'- MMP13 & GTCTTCATCGCCTGGACCATA \\
\hline
\end{tabular}

\section{Proliferation assays}

For the in vivo assay, $B R A F V 600 \mathrm{E}^{\mathrm{Scl}+}$ or control littermate mice aged 8 weeks were injected intra peritoneally with $1 \mathrm{mg}$ BrdU for seven consecutive days. Femurs were harvested $24 \mathrm{~h}$ after the last injection and processed into single cell suspension for BrdU incorporation by flow cytometry analysis. Tissue preparation and BrdU staining were performed according to the APC BrdU Flow kit protocol (BD PharMingen, 557892).

For the in vitro assays, BRAFV600E or NGFR transduced CD34 ${ }^{+}$HPC were kept in culture in Stemspan SFEM II media (STEMCELL Technologies). Transduced CD34 ${ }^{+} \mathrm{HPC}^{+}$were incubated from day 10 to day 13 with $10 \mu \mathrm{M}$ of BrdU supplemented daily in cell culture medium. Transduced HPC were harvested at day 14 and analyzed for BrdU incorporation by flow cytometry using the same kit used for the in vivo experiment. 
Cell Trace Violet: Transduced CD34 ${ }^{+}$HPC were labeled with $1 \mu$ M CFSE (Life Technologies) in PBS $/ 0.1 \%$ BSA for $10 \mathrm{~min}$ at $37^{\circ} \mathrm{C}$. The cells were analyzed 92 hours after the treatment with Cell Trace Violet.

\section{Competitive transplantation assays}

Femurs from 12 week-old $B R A F V 600 \mathrm{E}^{\mathrm{Scl}+}$ or $B R A F \mathrm{wt}^{\mathrm{Scl}+}$ mice were harvested 4 weeks after tamoxifen injections. Lineage negative $\mathrm{BM}$ cells from either $B R A F V 600 \mathrm{E}^{\mathrm{Scl}+}$ or $B R A F \mathrm{wt}^{\mathrm{Scl}+}$ mice (both $\mathrm{CD} 45.2^{+}$) were obtained using a MACS mouse lineage cell depletion kit (Miltenyi Biotec) and were injected intravenously together with lineage negative BM cells of the host type $\left(C D 45.1^{+}\right)$into lethally irradiated $C D 45.1^{+}$mice $(1,200$ rad delivered in two doses of 600 rad each, 3 hours apart) at a ratio of 2:1 (200,000 CD45.2 $\left.: 100,000 \mathrm{CD} 45.1^{+}\right)$. Levels of blood donor chimerism were analyzed by measuring the percentage of CD $45.2^{+}$cells among $\mathrm{CD}_{4} 5^{+}$ cells 4 and 8 weeks after transplantation.

\section{ELISA}

BM was prepared by flushing 2 femurs with $500 \mu$ l PBS. After pelleting the cells, supernatant was used for $\mathrm{BM}$ extra-fluid measurements and stored at $-80^{\circ} \mathrm{C}$. For detecting and quantifying proteins, commercially available ELISA kits for IL-1a (R\&D Systems, DY400), IL-1b (R\&D Systems, DY401), and IL-6 (R\&D Systems, DY406) were used.

Supernatant from transduced CD34 ${ }^{+}$HPC was harvested at different time points (day 7, 9 and 14) and stored at $-80^{\circ} \mathrm{C}$. For measurement of proteins levels, commercially available ELISA kits for IL-1a (Biolegend, 445807), IL-1b (Biolegend, 437007), IL-6 (Biolegend, 430507) and IL-8 (Biolegend, 431507) were used.

For human plasma specimens, blood was collected from pre-therapy pediatric patients with multisystem LCH and healthy pediatric controls in EDTA tubes, spun at $400 \mathrm{~g}$ for 30 minutes over Ficoll, then the plasma supernatant was collected, re-spun for 5 minutes, then purified supernatant was stored at $-80^{\circ} \mathrm{C}$. None of the plasma samples analyzed underwent more than 2 freeze/thaw cycles. Protein levels were determined using MagPix instrument (Luminex, Austin, TX). The concentration of each analyte was measured by comparing to the protein standards. IL-6 and IL- 8 were measured with the Millipore (Burlington, MA) Human Cytokine/Chemokine Panel I (1:2 dilution). 


\section{Therapeutic trials}

Rapamycin in vitro: Rapamycin (Invivogen, cat code tlrl-rap) was added at a concentration of $10 \mathrm{nM}$ at day 1 and day 4 following the transduction of CD34 ${ }^{+}$HPC. DMSO was used as mock treatment. GFP transduced cells were analyzed for myeloid surface marker expression (see antibody list) at day 8 post-transduction.

Rapamycin in vivo: Mice were treated with rapamycin or vehicle via intraperitoneal injection (dilution in $200 \mu \mathrm{L}$ of PBS per mouse) at $0.5 \mathrm{mg} / \mathrm{kg}$ body weight/ day for 10 consecutive days starting 15 days after the generation of $B R A F \mathrm{wt}^{\mathrm{Scl}+}$ or $B R A F \mathrm{~V} 600 \mathrm{E}^{\mathrm{Scl}+} \mathrm{BM}$ chimera. Mice were sacrificed at day 30 .

AP20187 in vivo: Mice were treated with vehicle (4\% ethanol: 10\% polyethylene glycol 400: $2 \%$ Tween-20 in distilled water) or AP20187 (purchased from Takara Bio, Cat. \# 635069 and diluted in 4\% ethanol: 10\% polyethylene glycol 400: 2\% Tween-20 in distilled water). AP20187 or diluent were administered every Monday, Wednesday and Friday (triweekly) for three consecutive weeks by gavage at $10 \mathrm{mg} / \mathrm{kg}$ body weight/ day, following tamoxifen injections.

ABT-263 (Navitoclax) in vivo: Mice were treated with diluent (10\% ethanol: $30 \%$ polyethylene glycol 400: 60\% Phosal 50 PG) or ABT-263 (diluted in 10\% ethanol: 30\% polyethylene glycol 400: 60\% Phosal 50 PG). ABT263 and vehicle were administered to mice by gavage at $50 \mathrm{mg} /$ kg body weight/ day for 3 consecutive weeks.

\section{Figures}



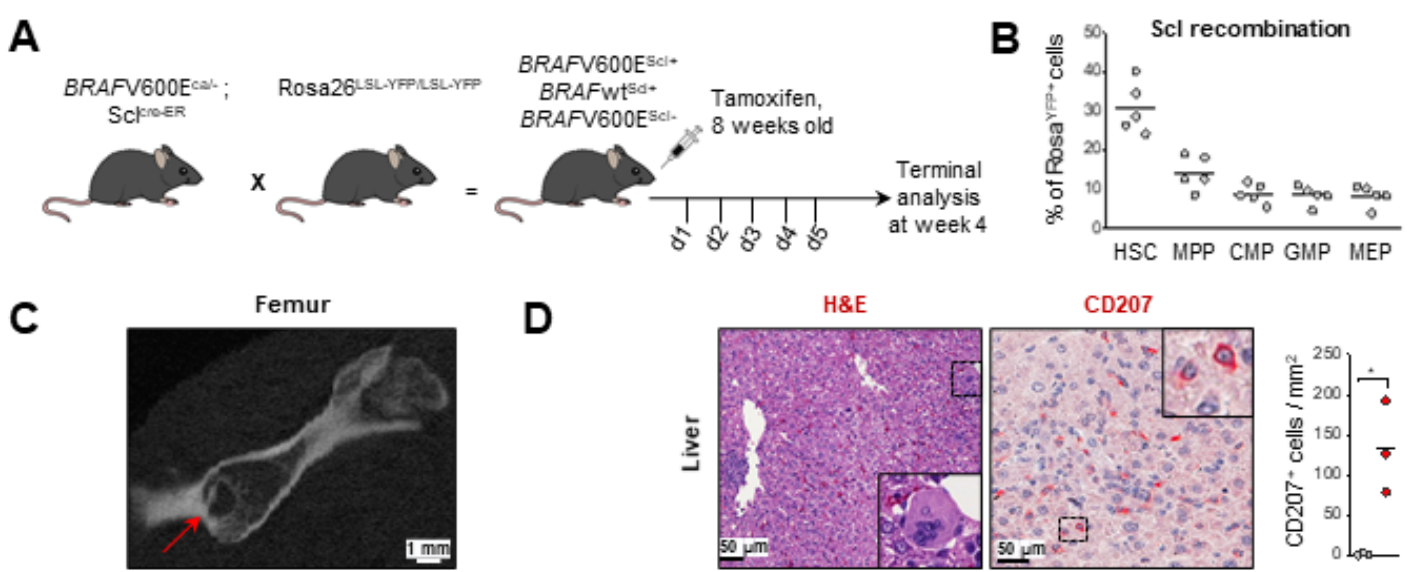

D
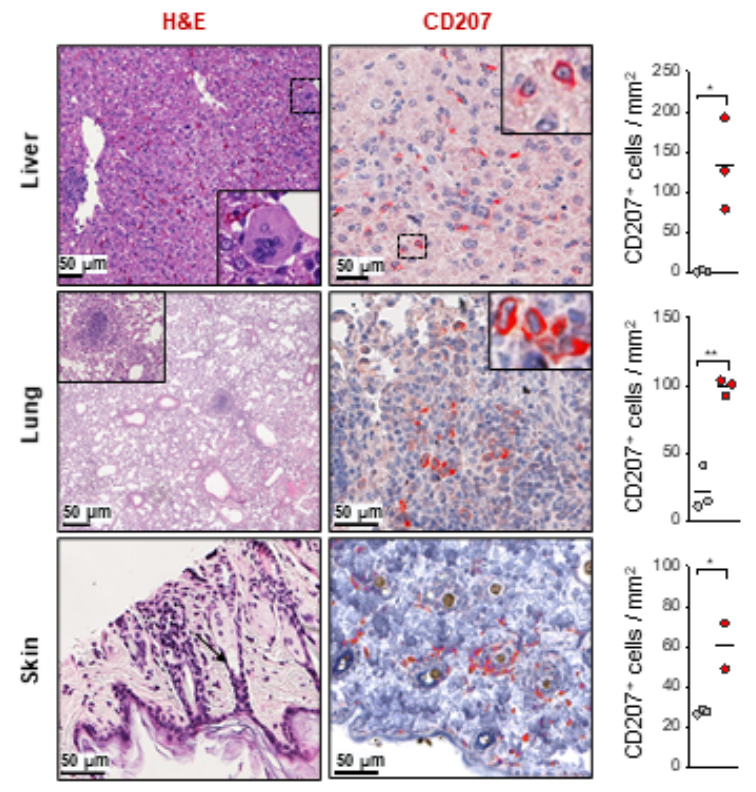

E
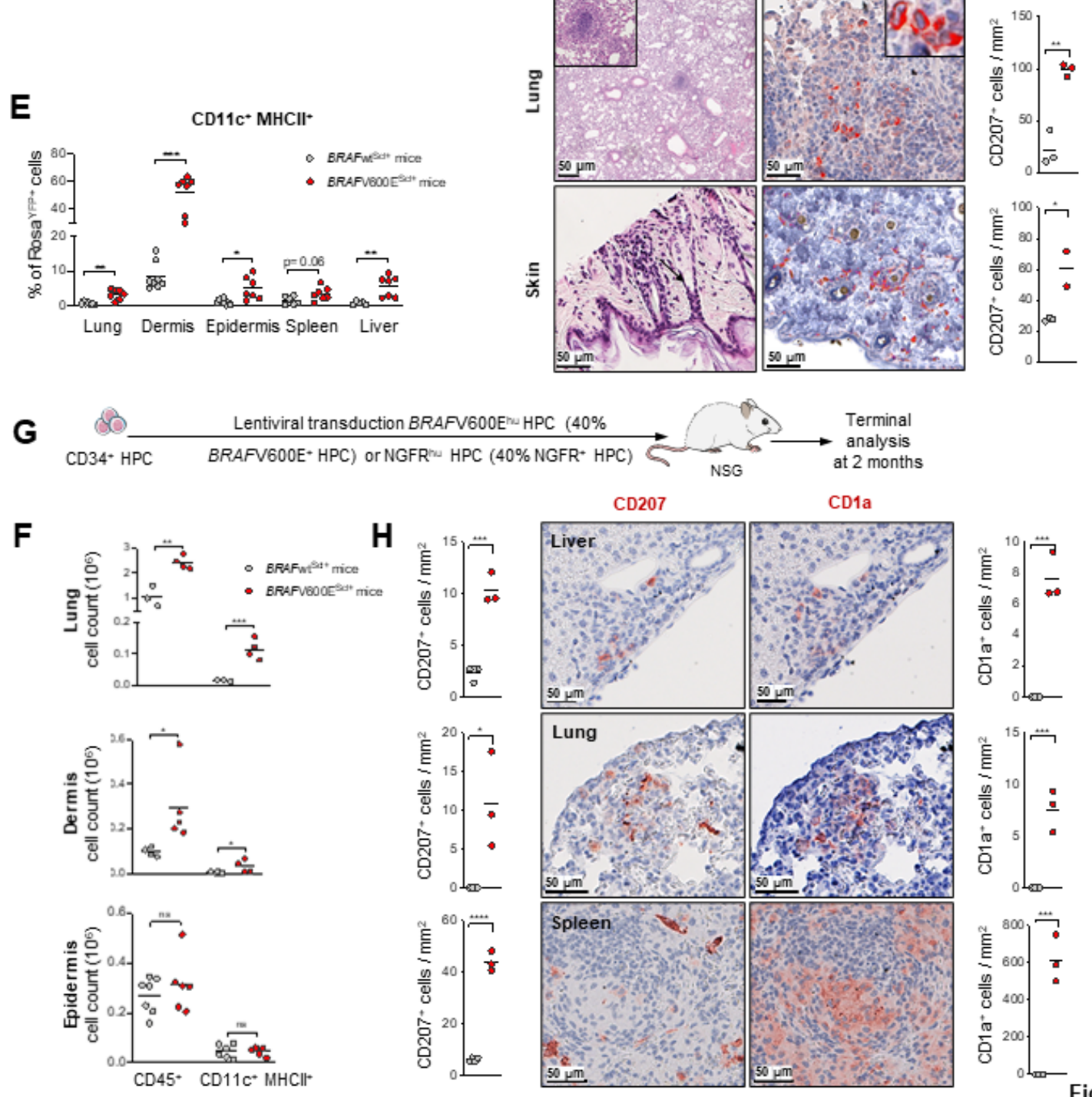

Figure 1

\section{Figure 1}

Expression of the BRAFV600E mutation in mouse and human multipotent hematopoietic progenitor cells (HPC) is sufficient to lead to LCH lesions (A) Cartoon shows the experimental breeding scheme used to generate BRAFV600EScl+ mice and control littermates. (B) Percentage of RosaYFP+ cells among purified hematopoietic progenitors in BRAFwtScl+ mice 4 weeks after tamoxifen injections. (C) Representative computerized tomography image of femur from BRAFV600EScl+ animal. The red arrow shows a 
pathognomonic granuloma. (D) Hematoxylin and eosin staining and CD207 immunohistochemistry staining of tissues isolated from BRAFV600EScl+ mice. We note the presence of multinucleated giant cells and granuloma like lesion. Graph represents the number of CD207+ cells per $\mathrm{mm} 2$ in tissue sections isolated from animals ( $n=2-3$ mice per group). (E) Percentage of CD11 + MHCll+ MNP population among RosaYFP+ cells in organs of BRAFV600EScl+ mice and control littermates. Data are representative of 3 experiments $(n=5-7)$. (F) Absolute number of total CD45+ immune cells and CD11c+MHCII+ MNP that populate the lung and the skin of BRAFV600EScl+ mice and control littermates. Data are representative of 3 experiments $(n=3-7)$. (G) Cartoon shows the scheme used to generate the humanized LCH mouse. $(\mathrm{H})$ Liver, lung and spleen tissues sections isolated from humanized mice reconstituted with BRAFV600Ehu HPC were stained with anti-CD207 and anti-CD1a antibodies. Graph represents the number of CD207+ or CD1a+ cells per mm2 in tissue sections isolated from animals $(n=2-3)$. Data are represented as mean \pm s.e.m; statistical significance analyzed by an unpaired two-sided t-test is indicated by ${ }^{*} p<0.05 ;{ }^{* \star} p<0.01 ;{ }^{* \star} p<0.001$. 
A
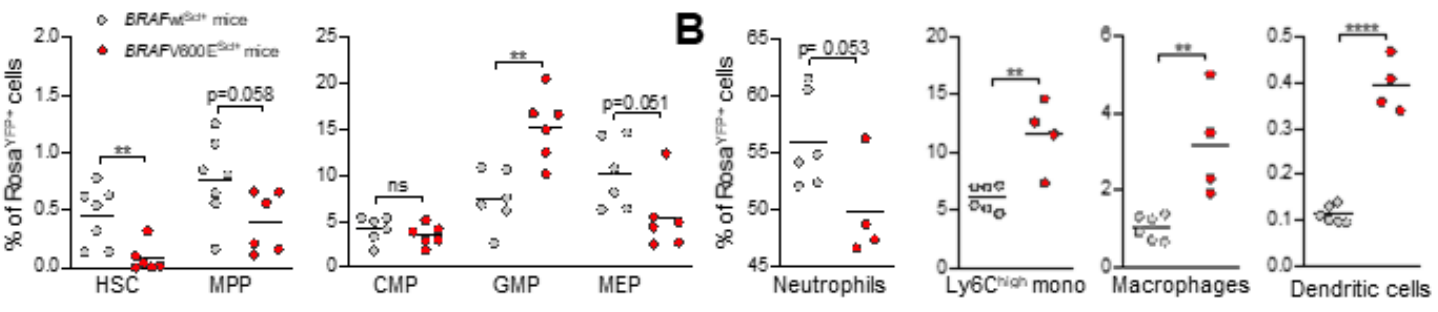

C
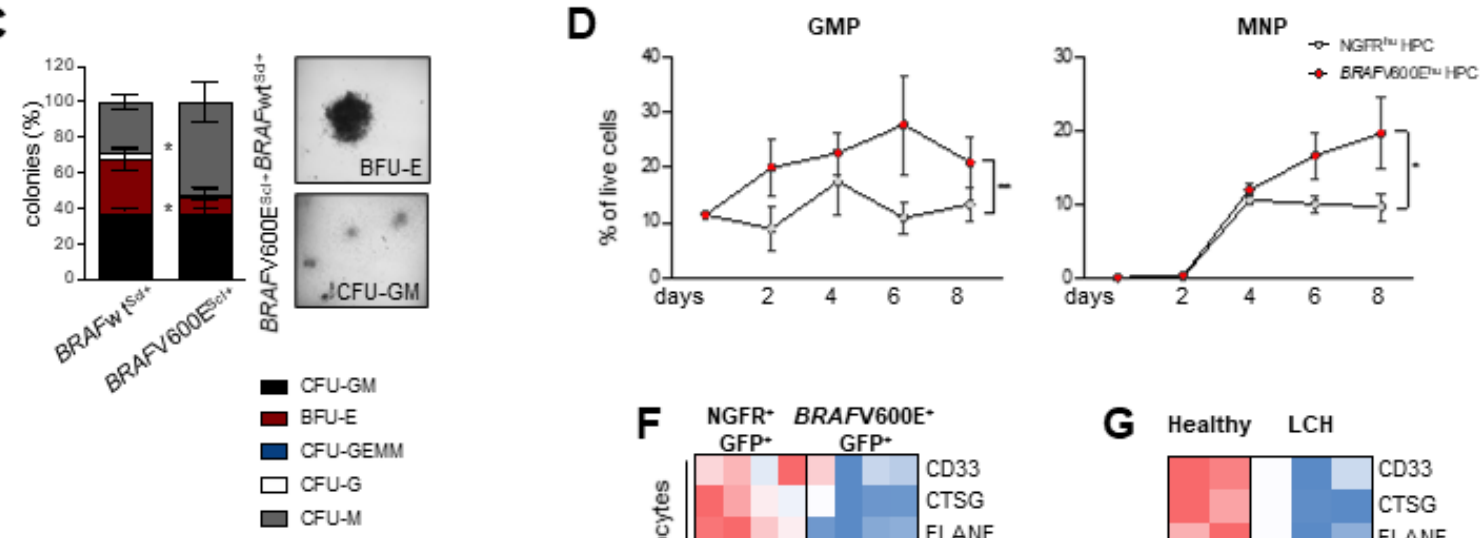

E
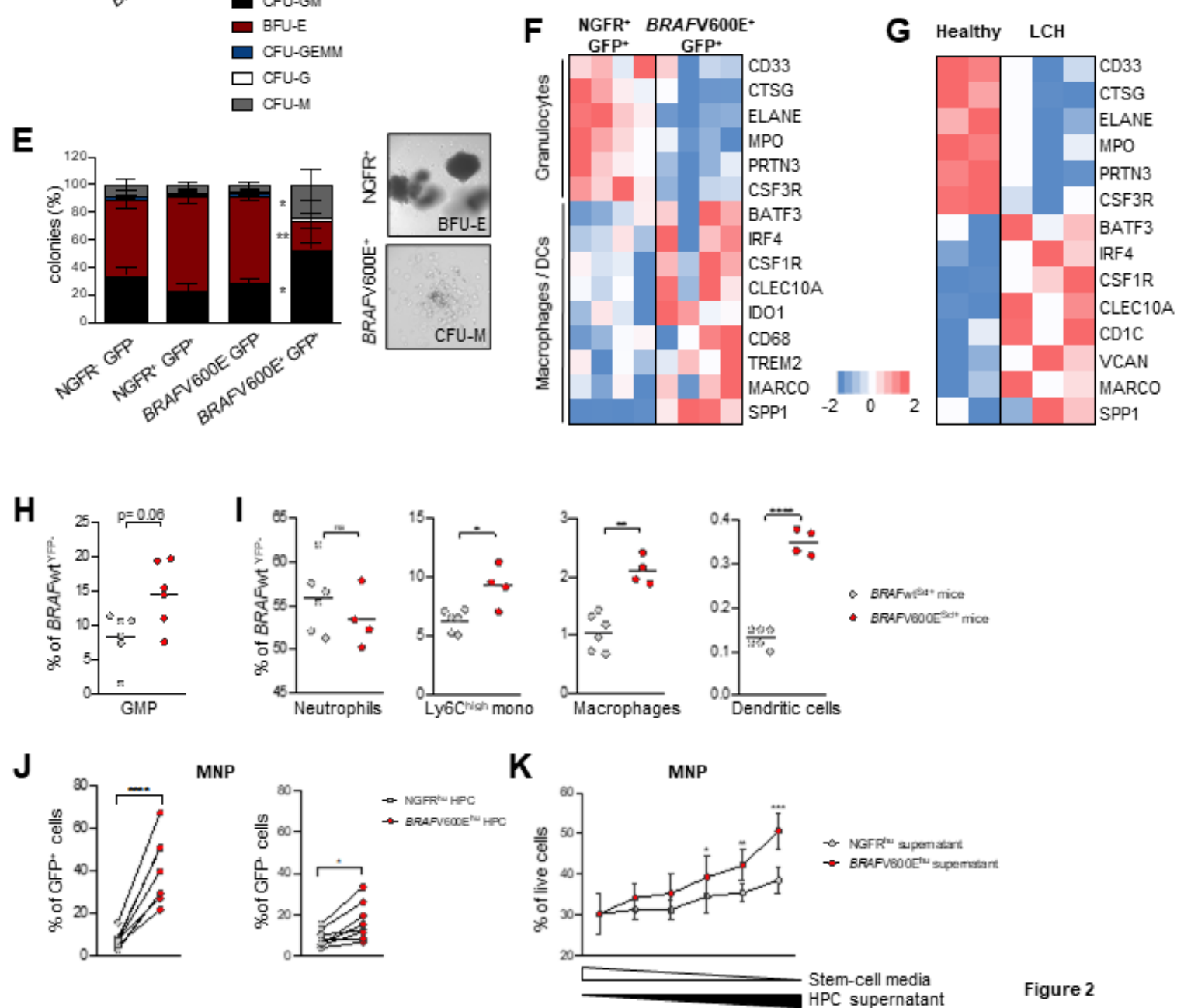

Figure 2

\section{Figure 2}

Expression of the BRAFV600E mutation in multipotent hematopoietic progenitors enforces their differentiation towards the mononuclear phagocyte (MNP) lineage. (A-C) BRAFV600EScl+ mice were generated as described in Fig $1 \mathrm{~A}$ and in these mice, RosaYFP+ cells mark BRAFV600E+ cells, while RosaYFP- cells mark BRAFV600E- cells. In BRAFwtScl+ control littermates, RosaYFP+ cells mark cells that underwent a cre recombination as well. (A) Graphs show the percentage of hematopoietic stem cells 
(HSC), multipotent progenitors (MPP), common myeloid progenitors (CMP), granulocytic myeloid progenitors (GMP) and megakaryocytic erythroid progenitors (MEP) among RosaYFP+ cells in the BM of BRAFV600EScl+ mice and BRAFwtScl+ control littermates. Data are representative of 3 experiments $(n=$ 6). (B) Percentage of neutrophils, Ly6Chigh monocytes, macrophages and dendritic cells among Rosa YFP+ cells in the BM of BRAFV600EScl+ mice and BRAFwtScl+ control littermates $(n=4-6)$. Data are representative of 3 experiments. (C) Colony-forming unit (CFU) assays were performed on purified lineage negative BM cells isolated from BRAFV600EScl+ mice or BRAFwtScl+ control littermates and cultured in the presence of methylcellulose. Graph shows the results of two experiments, with representative phase contrast photomicrographs of colonies. (D-F) Purified CD34+ HPC transduced with BRAFV600E (BRAFV600Ehu) or NGFR control (NGFRhu) lentiviral vectors were cultured in stem-cell media (Stemspan media supplemented with SCF, TPO and FLT3L) for 8 days. (D) Graphs show the percentage of GMP (defined as CD34+ CD38+ CD10- CD123high/int CD45RA+/-) (Lee et al., 2017) and the percentage of MNP (defined as CD66b- CD11 + MHC II+) among live cells. Data are representative of 3 experiments ( $\mathrm{n}=$ 3 donors) and analyzed by a two-way ANOVA. (E) Colony-forming unit (CFU) assays in methylcellulose performed on purified BRAFV600E- GFP- and BRAFV600E+ GFP+ isolated from HPC transduced with BRAFV600E lentiviral vector or purified NGFR+ GFP+ or NGFR- GFP- isolated from HPC transduced with NGFR lentiviral vector as described in supplementary Fig 3. Data are representative of 3 experiments, $(n=6$ donors). Representative phase contrast photomicrographs of colonies are shown. (F) Human CD34+ HPC transduced with BRAFV600E or control NGFR were cultured for 7 days in stem-cell media and analyzed using micro-array sequencing. Heat map representation of genes involved in granulopoiesis, and macrophage/dendritic cell lineage is shown ( $n=4$ donors per group). (G) Purified CD34+ BM cells were isolated from a healthy pediatric donor and from three LCH patients with known BRAFV600E+BM mononuclear cells and were analyzed using bulk RNA sequencing. Heat map representation of genes involved in granulopoiesis and macrophages/DC lineage is shown. (H-I) BRAFV600EScl+ mice and BRAFwtScl+ control littermates were generated as described in Fig 1A. The percentage of GMP $(H)$, neutrophils, Ly6Chigh monocytes, macrophages, and dendritic cells (I) among BRAFwt RosaYFP- cells in the BM of BRAFV600EScl+ mice and BRAFwtScl+ control littermates is shown. Data are representative of 3 experiments $(n=4-6)$. (J) Human CD34+ HPC were transduced with BRAFV600E or NGFR lentiviral construct and cultured in stem-cell media. Seven days later the percentage of CD11c+ and/ or CD14+ MNP cells among BRAFV600E (GFP+) or BRAFwt (GFP-) cells was measured by flow cytometry. Because the transduction efficiency is around $40 \%$ for both vectors, GFP+ cells mark BRAFV600E+ or NGFR+ cells, while GFP- cells mark BRAFwt or NGFR- cells among HPC transduced with the BRAFV600E or NGFR lentiviral construct, respectively. Data are representative of at least 3 experiments ( $n=8$ donors). (K) Healthy human CD34+ cord blood HPC were cultured in stem-cell media (concentration represented by the white triangle) in addition to supernatant isolated from HPC transduced with the BRAFV600E lentiviral construct or NGFR control (concentration represented by the black triangle). Graph shows the percentage of HPC differentiation into CD14+ MNP analyzed by flow cytometry after 5 days of culture. Data are representative of 3 experiments ( $n=4$ donors) and analyzed by a paired t-test. Data are represented as mean \pm s.e. $m ;{ }^{*} p<0.05 ;{ }^{* \star} p<0.01 ; * \star * p<0.001 ; * \star \star \star p<0.0001$ (unpaired two-sided t-tests, two-way ANOVA test for $2 \mathrm{D}$ and paired t-test for $2 \mathrm{~J}$ and $\mathrm{K}$ ). 

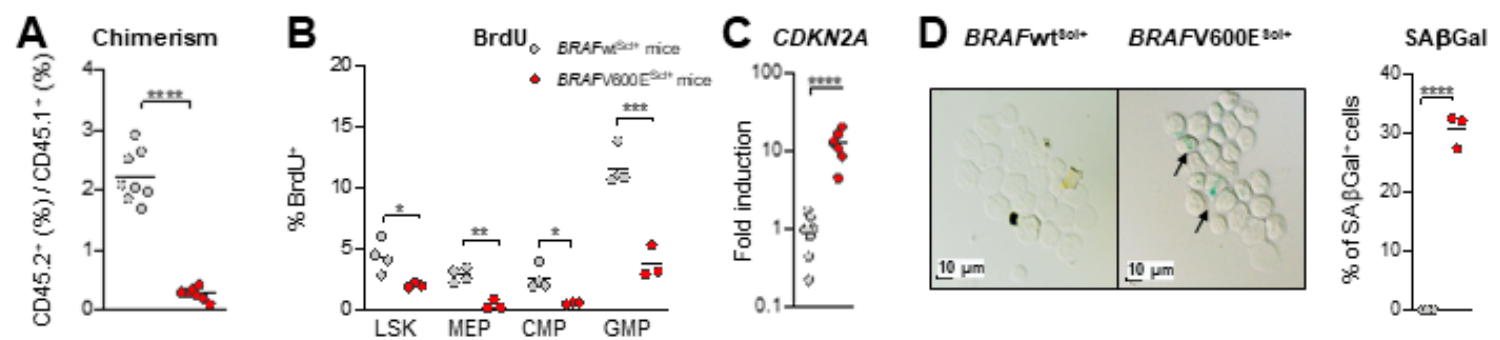

E
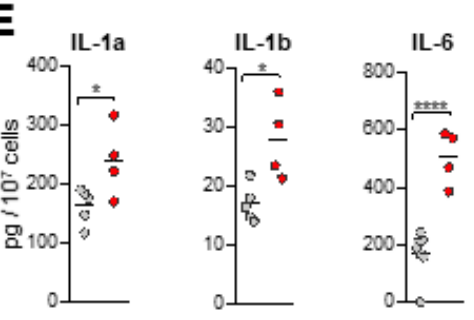

\section{$\mathbf{F}$}
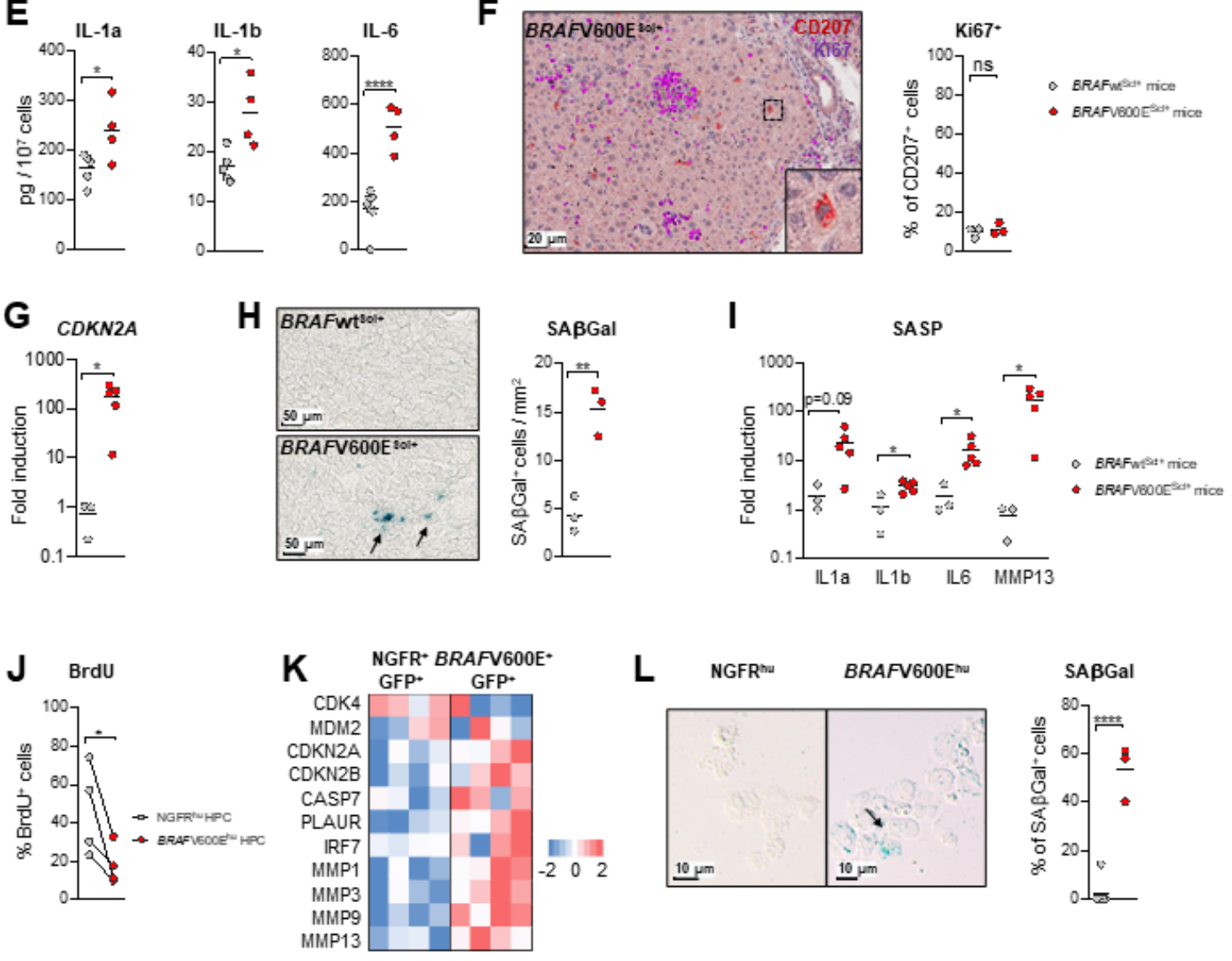

M
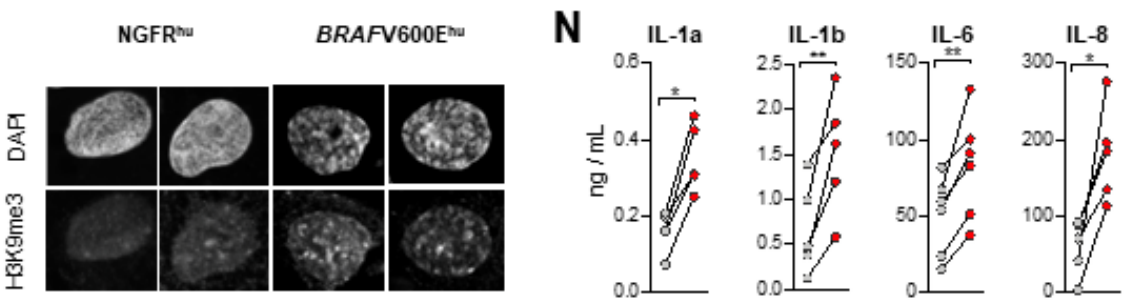

Figure 3

\section{Figure 3}

The BRAFV600E mutation drives mouse and human hematopoietic progenitors into senescence (A) Lineage negative BM cells isolated from either BRAFV600EScl+ CD45.2+ or BRAFwtScl+ CD45.2+ mice were injected intravenously together with lineage negative CD45.1+ BM cells into lethally irradiated CD45.1+ mice at a 2:1 ratio (CD45.2+: CD45.1+). Graph shows the ratio of CD45.2+ / CD45.1+ in the blood circulation in each group measured 4 weeks after transplantation using flow cytometry. Data are 
representative of 2 experiments $(n=8)$. (B-E) Bone marrow cells were isolated from BRAFV600EScl+ and BRAFwtScl+ control littermates and analyzed for (B) the percentage of BrdU expression in lineage- Sca-1+ c-Kit+ cells (LSK), MEP, CMP and GMP after 7 daily BrdU injections (1mg/day). Data are representative of 3 experiments $(n=3-4)$; (C) CDKN2A expression of purified lineage- BM cells measured by RT-qPCR (normalized to actin expression). Data are representative of 3 experiments ( $n=7-8)$; (D) SABGal activity of purified lineage- BM cells. Graph shows the percentage of SABGal+ cells among total cells $(n=3$ mice per group) (E) IL-1a, IL-1b and IL-6 protein levels in the BM supernatant detected by ELISA are shown $(n=4-$ 6 per group). (F-I) Liver tissue sections were obtained from BRAFV600EScl+ and BRAFwtScl+ control littermates and analyzed for (F) Ki-67+ (violet) cells among liver infiltrating CD207+ LCH cells (red). Graph shows the percentage of Ki-67+ cells among CD207+ cells in liver sections ( $n=3$ mice per group); $(G)$ CDKN2A expression by RT-qPCR (normalized to actin expression) ( $n=3-5$ per group); (H) SA 3 Gal activity. Graph shows the number of SABGal+ cells per $\mathrm{mm} 2$ in liver sections ( $\mathrm{n}=3$ mice per group) and $(\mathrm{I})$ expression of IL-1a, IL-1b, IL-6 and MMP13 by RT-qPCR normalized to actin expression ( $n=3-5$ per group). (J-N) Human CD34+ cord blood HPC were transduced with BRAFV600E (BRAFV600Ehu) or NGFR control (NGFRhu) lentiviral vectors, cultured in stem-cell media and analyzed for $(\mathrm{J}) \mathrm{BrdU}$ expression after daily pulse of BrdU from day 10 to day 13 ( $n=4$ different donors); (K) gene expression of senescence associated genes using microarray expression profiling 7 days after transduction ( $n=4$ donors); $(L)$ SABGal activity 9 days after the transduction. The percentage of SABGal+ cells among total cells is indicated. (M) DAPI and H3K9me3 immuno-fluorescence co-staining of NGFRhu and BRAFV600Ehu HPC 9 days after transduction, images representative of senescence-associated-heterochromatin-foci (SAHF) (N) IL-1a, IL-1b, IL-6 and IL-8 levels in the culture supernatant 7 days after HPC transduction ( $n=4-6$ donors). Data are represented as mean \pm s.e.m; statistical significance analyzed by an unpaired and paired (for 3J and N) two-sided t-test is indicated by ${ }^{\star} \mathrm{p}<0.05 ; * \star \mathrm{p}<0.01$; ${ }^{* \star} \mathrm{p}<0.001$; ${ }^{\star \star \star \star} \mathrm{p}<0.0001$. 

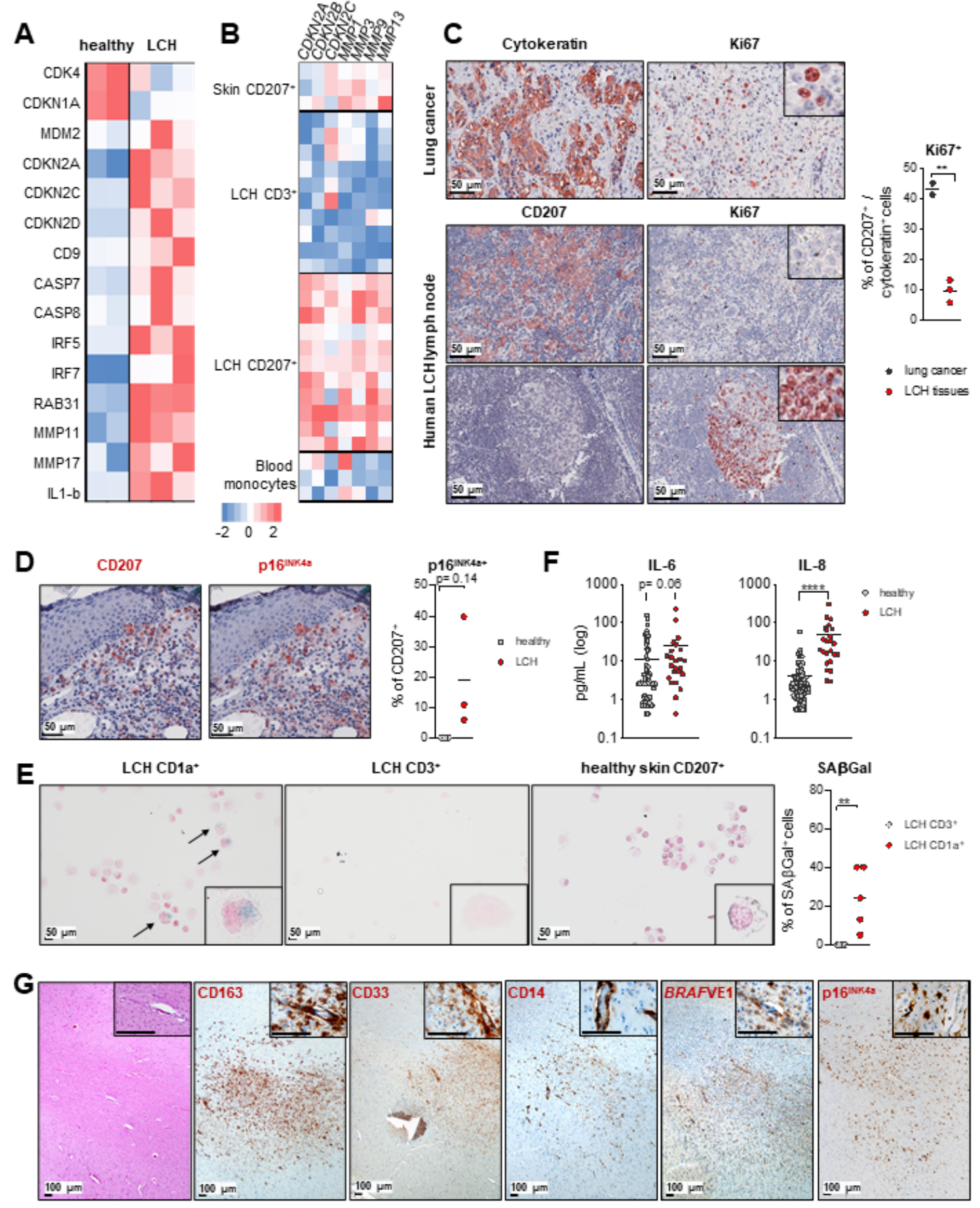

Figure 4

\section{Figure 4}

The BRAFV600E mutation induces a senescence program in human LCH lesions (A) Heat map representation of senescence-associated gene expression measured by RNAseq in purified CD34+ BM cells isolated from three LCH patients and one pediatric healthy donor (performed in duplicate). (B) Skin CD207+ cells were isolated from healthy skin, CD3+ and CD207+ cells were purified from LCH lesions, and circulating CD14+ cells were isolated from healthy pediatric donors and analyzed for gene 
expression profile using microarray. The expression profile of CDKN2A, CDKN2B, CDKN2C, MMP1, MMP3, MMP9 and MMP13 is shown. (C) FFPE sections of LCH lymph node lesions from three different patients were immunostained for CD207 and Ki-67, and FFPE lung cancer sections were immunostained for cytokeratin and $\mathrm{Ki}-67$. Images at the top show the high proliferation index of lung cancer. Images at the bottom show the same LCH donor with LCH in a lymph node. The middle panel shows low proliferative index of the LCH as compared to the bottom panel of uninvolved lymphoid follicle with its typical proliferative activity in the polarized germinal center. Graph represents the \% of Ki-67+ cells among CD207 positive cells in LCH tissue or among cytokeratin positive cells in lung cancers. (D) Skin tissue sections isolated from LCH patients and healthy age-matched donors were stained for CD207 and p16INK4a using immunohistochemistry. One representative image is shown $(n=3)$. Graph shows the percentage of p16INK4a positive cells among CD207 positive cells $(n=3$, for each group). (E) SABGal activity of human LCH lesions. CD207+ cells and CD3+ cells were sorted from LCH lesions $(n=5)$, healthy skin and healthy tonsil and stained for SABGal activity. Graph shows the \% of SABGal+ cells among CD207+ cells and CD3+ cells, highlighting that the staining occurs mostly in LCH cells. (F) Graphs show IL- 6 and IL-8 protein levels in the plasma of LCH patients and age matched healthy donors $(n=24$ multisystem LCH patients, $n=89$ healthy pediatric donors). (G) Autopsy brain sections from a patient with neurodegenerative-LCH and circulating BRAFV600E+ peripheral blood cells. The H\&E image shows a temporal lobe white matter injury with increased numbers of infiltrating plump cells. The immunohistochemical characterization of the enlarged plump cells shows a positivity for CD163, CD33, CD14, BRAFVE1 and p16INK4a. (*indicates perivascular space). Data are represented as mean \pm s.e.m; statistical significance analyzed by an unpaired two-sided t-test is indicated by $* p<0.05 ; * \star p<0.01$; ** $\mathrm{p}$ $<0.001 ; * \star \star \star p ~ p ~ 0.0001$. 
A
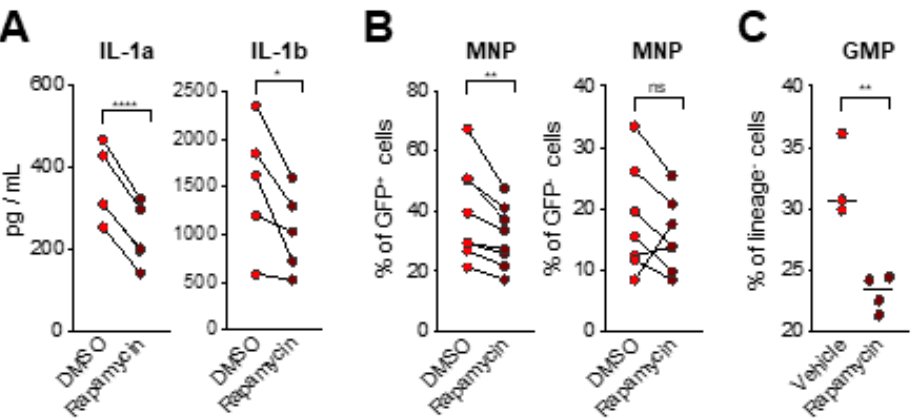

D Dendritic cells Macrophages Neutrophils
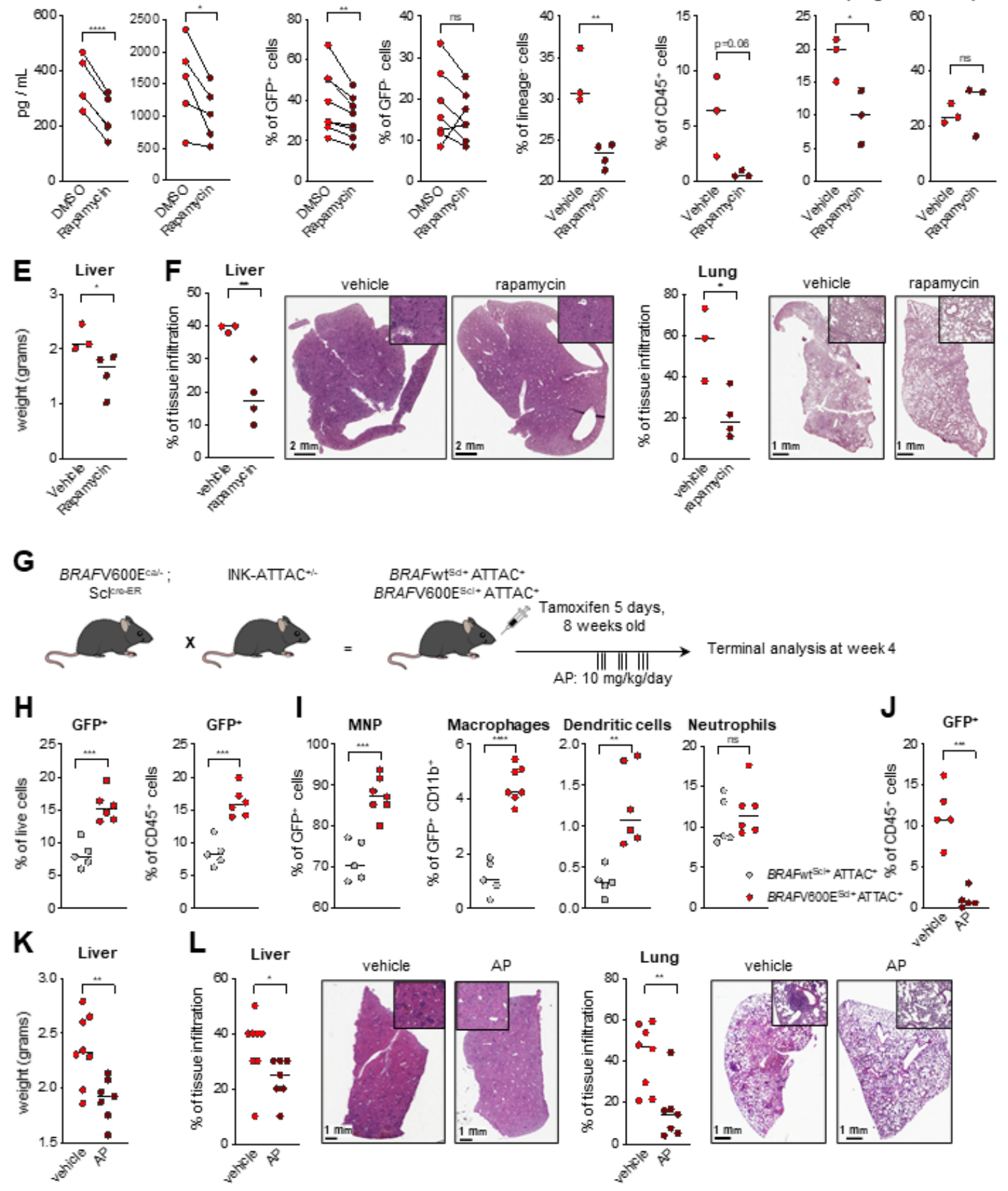

Figure 5

\section{Figure 5}

SASP inhibition and eradication of senescent cells improve LCH outcome (A-B) BRAFV600Ehu transduced CD34+ HPC were cultured in stem-cell media and treated at day 1 and day 4 with rapamycin (10 nM) or DMSO. (A) Graphs show IL-1a and IL-1b protein levels in the supernatant of CD34+ HPC 7 days after transduction ( $n=4-5$ different donors). (B) The percentage of MNP (CD11c+ and/or CD14+) among total GFP+ BRAFV600E+ and among total GFP- BRAFV600E- within cultures of BRAFV600E 
transduced HPC (BRAFV600Ehu) that were treated with rapamycin or DMSO diluent, was quantified by flow cytometry after 7 days of culture. (C-E) BRAFV600EScl+ mice were treated with rapamycin $(0.5 \mathrm{mg} /$

$\mathrm{kg}$ body weight/ day) or vehicle control for 10 days (C) Percentage of GMP (defined as DAPI- lineageckit+ Sca- CD16/32+ CD34high/int) among lineage negative BM cells and (D) The percentage of dendritic cells, macrophages and neutrophils among total CD45+ BM cells were measured using flow cytometry, $(n=3-4)$. (E) Liver weight in each group $(n=3-4)$. Data are representative of 2 experiments. $(F)$ The percentage of tissue infiltration in liver and lung is shown with representative image of H\&E staining of tissues isolated from BRAFV600EScl+ mice. (G) Cartoon shows the experimental breeding scheme and treatment strategy used to generate BRAFV600EScl+ ATTAC+ mice and control littermates. $(\mathrm{H}-\mathrm{l})$ BRAFV600EScl+ ATTAC+ mice and BRAFwtScl+ ATTAC+ control littermates were treated by tamoxifen for five days and sacrificed 4 weeks later. $(H)$ The percentage of senescent-p16INK4a overexpressing cells was assessed by flow cytometry in the bone marrow from BRAFV600EScl+ ATTAC+ mice and control mice $(n=5-6)$. Graph shows the percentage of GFP+ cells among live cells and among CD45+ cells, suggesting that senescent cells are exclusively hematopoietic cells. (I) The nature of senescent-p16INK4a positive cells was assessed by flow cytometry. Graph shows the percentage of CD11b+ myeloid cells among GFP+ senescent cells, and the percentage of macrophages, dendritic cells and neutrophils among GFP+ CD11b+ myeloid senescent cells in BRAFV600EScl+ ATTAC+ and control animals, highlighting that senescent cells in BRAFV600EScl+ ATTAC+ mice are almost exclusively myeloid cells and among them there is an accumulation of macrophages and dendritic cells, rather than neutrophils. (J-L) Following tamoxifen injections, BRAFV600EScl+ ATTAC+ mice and BRAFwtScl+ ATTAC+ control littermates were treated by AP or vehicle during three weeks and sacrificed 4 weeks after tamoxifen injections. $(\mathrm{J})$ The percentage of senescent-p16INK4a overexpressing cells was assessed by flow cytometry in the bone marrow from untreated and treated BRAFV600EScl+ ATTAC+ mice $(n=5)$. Graph shows the percentage of GFP+ cells among CD45+ cells. $(K)$ Liver weight in each group $(n=8)$. ( $L)$ The percentage of tissue infiltration in liver and lung are shown with representative image of hematoxylin and eosin staining of tissues isolated from untreated and treated BRAFV600EScl+ ATTAC+ mice $(n=8)$. Data are representative of 3 experiments and are represented as mean \pm s.e.m, statistical significance analyzed by an unpaired and paired (for $5 A$ and $B$ ) two-sided t-test is indicated by ${ }^{*} p<0.05 ;{ }^{* \star} p<0.01$; ${ }^{* \star} p<0.001$.

\section{Supplementary Files}

This is a list of supplementary files associated with this preprint. Click to download.

- SupplementaryTables.docx

- revisedFIGURESFINALandSupplementaryFigures.pptx

- SupplementaryFigureLegends.docx 